\title{
Seismic and mechanical studies of the artificially triggered rockfall at Mount Néron (French Alps, December 2011)
}

\author{
P. Bottelin ${ }^{1}$, D. Jongmans ${ }^{1}$, D. Daudon ${ }^{2}$, A. Mathy ${ }^{3}$, A. Helmstetter ${ }^{1}$, V. Bonilla-Sierra ${ }^{2}$, H. Cadet ${ }^{3}$, D. Amitrano ${ }^{1}$, \\ V. Richefeu ${ }^{2}$, L. Lorier ${ }^{3}$, L. Baillet ${ }^{1}$, P. Villard ${ }^{2}$, and F. Donzé ${ }^{2}$ \\ ${ }^{1}$ ISTerre, Université de Grenoble 1, CNRS, BP 53, F-38041 Grenoble CEDEX 9, France \\ ${ }^{2}$ Laboratoire 3S-R, Université de Grenoble 1, G-INP, CNRS, BP 53, F-38041 Grenoble CEDEX 9, France \\ ${ }^{3}$ Société Alpine de Géotechnique (SAGE), 2 rue de la Condamine, Gières, France \\ Correspondence to: P. Bottelin (pierre.bottelin@ujf-grenoble.fr)
}

Received: 18 June 2013 - Published in Nat. Hazards Earth Syst. Sci. Discuss.: 14 February 2014

Revised: - - Accepted: 1 November 2014 - Published: 2 December 2014

\begin{abstract}
The eastern limestone cliff of Mount Néron (French Alps) was the theater for two medium-size rockfalls between summer and winter 2011. On 14 August 2011, a $\sim 2000 \mathrm{~m}^{3}$ rock compartment detached from the cliff, fell $100 \mathrm{~m}$ below and propagated down the slope. Although most of the fallen rocks deposited on the upper part of the slope, some blocks of about $15 \mathrm{~m}$ in size were stopped by a ditch and an earthen barrier after a run-out of $800 \mathrm{~m}$. An unstable overhanging $\sim 2600 \mathrm{~m}^{3}$ compartment remained attached to the cliff and was blasted on 13 December 2011. During this artificially triggered event, 7 blocks reached the same ditch, with volumes ranging from 0.8 to $12 \mathrm{~m}^{3}$. A semi-permanent seismic array located about $2.5 \mathrm{~km}$ from the site recorded the two events, providing a unique opportunity to understand and to compare the seismic phases generated during natural and artificially triggered rockfalls. Both events have signal duration of $\sim 100 \mathrm{~s}$ with comparable maximum amplitudes recorded at large distances (computed local magnitude of 1.14 and 1.05 , respectively), most of the energy lying below $20 \mathrm{~Hz}$. Remote sensing techniques (photogrammetry and lidar) were employed before and after the provoked rockfall, allowing the volume and fracturing to be characterized. This event was filmed by two video cameras, and the generated ground motions were recorded using two temporary $3 \mathrm{C}$ seismic sensors and three seismic arrays deployed at the slope toe.

Videos and seismogram processing provided estimates of the propagation velocity during the successive rockfall phases, which ranges from 12 to $30 \mathrm{~m} \mathrm{~s}^{-1}$. The main seismic phases were obtained from combined video and seismic
\end{abstract}

signal analyses. The two most energetic phases are related to the ground impact of fallen material after free fall, and to individual rock block impacts into the ditch and the earthen barrier. These two phases are characterized by similar lowfrequency content but show very different particle motions. The discrete element technique allowed reproducing the key features of the rockfall dynamics, yielding propagation velocities compatible with experimental observations.

\section{Introduction}

Rockfalls are sudden events which are able to cause considerable loss of life and property, depending on their location and characteristics. As their occurrence is still difficult to predict, field measurements during rockfalls are scarce, which makes it difficult to gain information on their dynamics. In recent years, increasing attention has been paid to rockfall-induced seismic signals recorded by permanent arrays, which often constitute the only information available during the events (Dammeier et al., 2011). In parallel to seismic record processing, numerical modeling of rockfalls has developed considerably with the aim of gaining knowledge on the rock mass propagation and making the link between landslide dynamics and generated seismic waves (e.g., Favreau et al., 2010). In this paper, the term "rockfall" describes all events with a rock mass detaching and propagating on a steep slope, regardless of volume, dynamics or failure mode. When a specific rockfall type will be discussed the terms "rock avalanches", "mid-size rockfalls" and "block 
falls" will be employed for large $\left(>10^{6} \mathrm{~m}^{3}\right)$, intermediate $\left(10^{3}-10^{6} \mathrm{~m}^{3}\right)$ and small volumes $\left(<10^{3} \mathrm{~m}^{3}\right)$, respectively. Block falls are characterized by the independent movement of individual particles, in contrast to rock avalanches that generate extremely rapid flows of debris (Evans and Hungr, 1993).

Seismic records induced by rockfalls have specific characteristics that can be used for event detection, identification and location. Such signals generally last about tens to hundreds of seconds with an emergent onset and progressive decaying tail (Dammeier et al., 2011). The seismogram duration is linked to the duration of the propagation, whereas its shape reflects the dynamics (sometimes in several stages) of the event (Deparis et al., 2008; Hibert et al., 2011). Hibert et al. (2011) studied the rockfall activity that occurred in the Dolomieu crater (Piton de la Fournaise volcano, Réunion) during some periods in 2006 and 2007. These granular flow like events occurred in very destructured rocks and the signal envelope showed a smooth cigar shape similarly to snow avalanches (Biescas et al., 2003; Surinach et al., 2005) or lahars (Cole et al., 2009), reflecting progressive initiation, propagation and deposition phases. In contrast, other studies have shown that rockfalls have more irregular envelopes with some high-amplitude peaks, probably generated by blocks impacts (Deparis et al., 2008; Vilajosana et al., 2008; Helmstetter and Garambois, 2010; Dammeier et al., 2011). In most cases, no clear $P$ and $S$ wave arrivals are spotted and the seismogram is dominated by surface waves (Rousseau, 1999; Deparis et al., 2008; Helmstetter and Garambois, 2010). For all the above-mentioned events, most of the energy lies between tenths of $\mathrm{Hz}$ and dozens of $\mathrm{Hz}$, with predominant frequency about a few Hz (Dammeier et al., 2011; Hibert et al., 2011). The low-frequency limit is controlled by the event size whereas the high-frequency corner depends also on the distance to the source.

Rockfall-induced signals show characteristic timefrequency distributions, hence spectrograms are frequently used to gain insights into rockfall dynamics and to separate phases which occur at close times but with different frequency content. In their studies, Surinach et al. (2005) and Dammeier et al. (2011) reported that rockfall spectrograms show a typical triangular shape that could be related to source effects, material entrainment during propagation and/or progressive failure and individual block impacts (Norris, 1994; McSaveney and Downes, 2002). All these characteristics can be used for event detection at different scales (Helmstetter and Garambois, 2010; Yamada et al., 2012; Kao et al., 2012).

Several studies have shown that rockfalls can be located using records from multiple seismic stations. When computed in near-realtime, this information can be of critical importance for rescue organizations. As no clear $P$ and $S$ waves are visible on seismograms, conventional earthquake location techniques cannot be applied. Specific methods have been developed, based on the seismogram envelope (Yamada et al., 2012, 2013), amplitudes (Battaglia et al., 2003), wave polarization (Vilajosana et al., 2008), signal cross-correlation (Lacroix and Helmstetter, 2011) and arrival times (Hibert, 2012). Due to the emergent seismogram onset, this last technique requires advanced picking methods (e.g., Baillard et al., 2013). In addition to rockfall detection, identification and location, numerous studies have focused on determining the fallen volume using seismic signals. Norris (1994) and McSaveney and Downes (2002) found a linear relationship between volume and seismogram amplitude for rock avalanches in USA and New Zealand, although the relationship appeared site-specific. In the same volume range, Yamada et al. (2012) observed a linear relationship between signal energy (square of the amplitude) and the square of the landslide volume. Dammeier et al. (2011) studied a set of 20 mid-size rockfalls in the Alps. The fallen volume was best correlated with signal duration, in good agreement with Deparis et al. (2008) that related signal duration with potential energy and run-out. However, Hibert et al. (2011) showed that the seismogram duration is controlled by numerous parameters, reflecting complex and simultaneous phenomena. They proposed a method for granular flows which uses the seismic energy $\left(E_{\mathrm{s}}\right)$ dissipated over the entire signal to derive the potential energy and the fallen volume.

The conversion between initial potential energy $\left(E_{\mathrm{p}}\right)$ and seismic energy $\left(E_{\mathrm{s}}\right)$ has been studied by many authors. Weichert (1994) computed conversion ratios of about $10^{-3}$ $10^{-7}$ for four rock avalanches and suggested that $E_{\mathrm{S}} / E_{\mathrm{p}}$ depends on the slope angle. For mid-size rockfalls, Deparis et al. (2008) observed ratios in the range $10^{-3}$ to $10^{-6}$, in good agreement with Hibert et al. (2011), who found $E_{\mathrm{s}} / E_{\mathrm{p}} \approx$ $10^{-4}$. In contrast, Vilajosana et al. (2008) determined a high conversion ratio $(0.25)$ for the impact of a mass $\left(75 \mathrm{~m}^{3}\right)$ on a terrace after a $120 \mathrm{~m}$ free fall. The $E_{\mathrm{s}} / E_{\mathrm{p}}$ conversion ratio appears then highly variable, and is probably a function of the fallen volume, block unitary size, fall type, slope angle and geotechnical ground conditions (Hibert, 2012).

Besides the experimental approach, numerical modeling techniques have been increasingly used to reproduce the behavior of rockfalls, pursuing the ultimate goal of propagation prediction (Hungr et al., 2005). Rockfall numerical simulations can be divided into two main families. First, granular numerical methods - which simulate a macroscopic behavior using microscopic interacting particles - were developed and have been applied to rockfalls with promising results (Dorren, 2003; Cleary and Prakash, 2004). These methods have been successfully compared with laboratory experimental tests (Banton et al., 2009; Richefeu et al., 2012) but still need validation on real cases. These methods are suitable to model a large range of rockfall volumes, including moderate volumes such as mid-size rockfalls. Another approach consists of simulating the fallen mass as a depth-averaged flow motion (Iverson, 1997; Mangeney-Castelnau, 2003), which provides accurate results for large volumes of granular ma- 

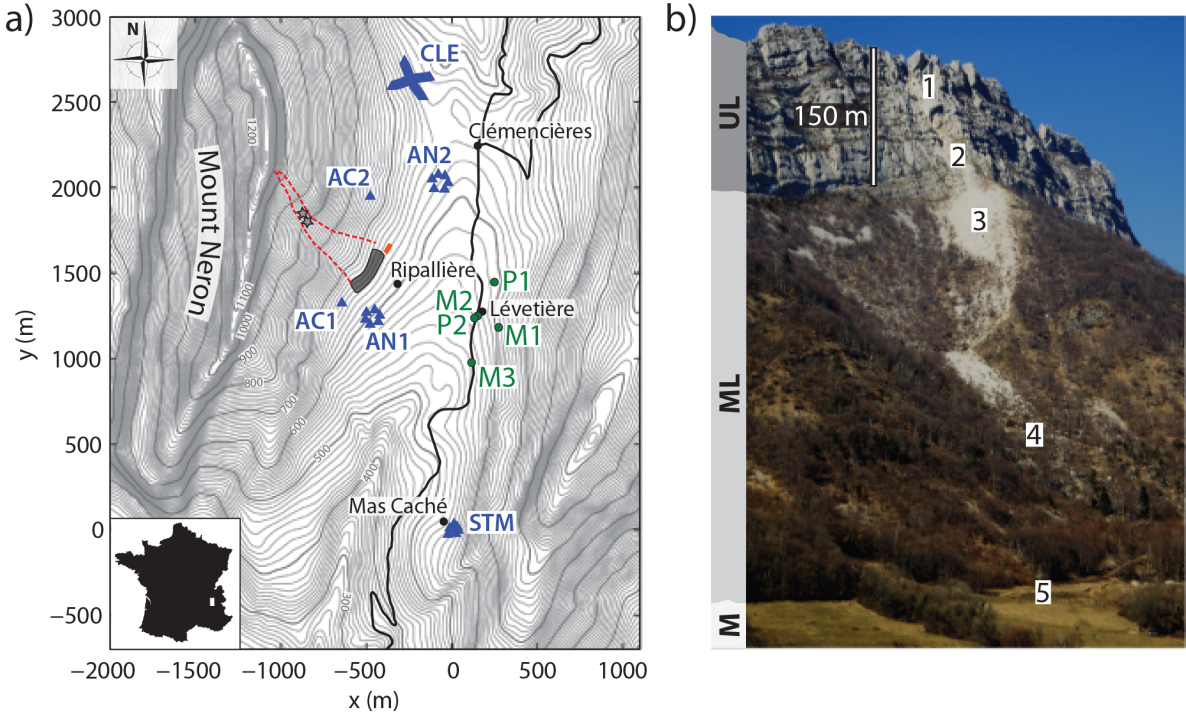

Figure 1. Panel (a): map of the settings, the topography is shown by grey contour lines and the major roads are marked with black thick lines. Black dots point out the hamlets. The red dashed line demarcates the rockfall propagation zone for the provoked event. The footprint of the ditch-earthen barrier is marked out with the dark grey polygon, and the flexible rockfall barrier is shown by the thick orange line. Blue triangles point out the seismic sensors. The green dots indicate the location of cameras used for photogrammetric analysis (P1 and P2) or event shooting (M1 to M3). The two grey stars show the location of the block bounces studied in Sect. 3.4. Panel (b): picture of Mount Néron taken from the southeast (Mas Caché) after the provoked event, with Urgonian limestone (UL), marly limestone (ML) and marls (M) indicated. (1) rockfall scar (light grey), (2) zone of mass impact in the lower part of the cliff, (3) scree deposits, (4) forest and (5) ditch and earthen barrier system.

terial such as rock avalanches (Pirulli and Mangeney, 2008; Moretti et al., 2012). For most of the studies, the efficiency of simulation models is assessed by comparison between the experimental and numerical deposit geometries.

Recent numerical models allow computing synthetic seismograms induced by large, granular rockfalls (i.e., rock avalanches), which allows a physical, quantitative and timedependent comparison with the experimentally recorded ground motion (Favreau et al., 2010). Seismic signal generation processes are related to flow dynamics and trajectory changes (Surinach et al., 2001; Brodsky et al., 2003; Favreau et al., 2010; Schneider et al., 2010; Allstadt, 2013) as well as changes in coupling with topography (Caplan-Auerbach and Huggel, 2007; Mangeney et al., 2007). Thanks to the low-frequency content of the seismograms, the waveform is preserved even for large source-sensor distances allowing the signals to be inverted. The seismic source can be modeled as a single horizontal force (Kanamori and Given, 1982; Kanamori et al., 1984; Dahlen, 1993) in which magnitude and direction vary over time and depend on the fallen volume, basal friction and dynamic effects (La Rocca et al., 2004). Sliding mass models (Brodsky et al., 2003; Allstadt, 2013; Yamada et al., 2013) or numerical depth-averaged flows models (Favreau et al., 2010; Schneider et al., 2010; Moretti et al., 2012) showed their ability to reproduce the seismic source characteristics for volcanic, rocky or rock-ice debris flows.
The case study of the Néron site, where two mid-size rockfalls of similar volumes $\left(\sim 2 \times 10^{3} \mathrm{~m}^{3}\right)$ occurred at the same place, offers an opportunity to improve our understanding of rockfall kinematics and its link with induced seismic signals. Video clips and seismic signals recorded during the provoked rockfall were jointly interpreted to determine the chronology of the successive rockfall phases and to characterize them in terms of energy and propagation velocities. 3-D modeling of the rockfall propagation was performed and calibrated on the deposit observations to compare numerical propagation velocities with experimental data.

\section{Site description}

Mount Néron is located $5 \mathrm{~km} \mathrm{NW}$ of Grenoble (Isère, France), at the southern end of the Chartreuse carbonate massif (Fig. 1a). The upper layer of its eastern slope is $150 \mathrm{~m}$ high (between 1150 and $1300 \mathrm{~m}$ in altitude) and made up of lowerUrgonian massive limestone (Fig. 1b). Below the cliff, a $40^{\circ}$ inclined slope (1150-600 m) is first covered by scree deposits overlying marly limestone, as its lower part shows a gentle slope with marl outcrops (Gidon and Arnaud, 1978). In summer 2003, the $S A G E$ engineering office detected a $4700 \mathrm{~m}^{3}$ unstable rock column in the limestone cliff, between $1210 \mathrm{~m}$ and $1260 \mathrm{~m}$ altitude.

A field structural analysis of the cliff revealed that the back of the unstable column was bounded by a potential 

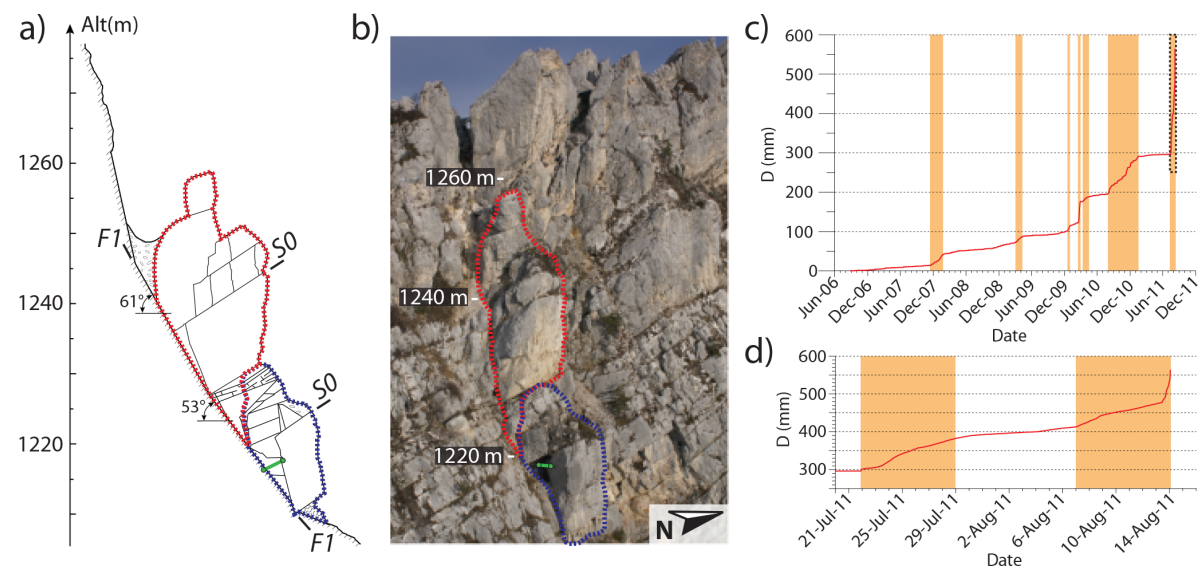

Figure 2. Panel (a): 2-D schematic cross-section of the unstable column. The cliff is indicated with the hatched line, discontinuities are shown with black lines. Panel (b): picture of the unstable rock column before the two rockfalls, taken from the southeast. Altitude is given with the white marks. For (a) and (b), blue and red dashed lines demarcate the natural and blasted compartments, respectively. The location of the extensometer E1 installed between the rock mass and the lower part of the unstable column is shown by the green line. Panel (c): displacement versus time measured by E1, from the setup in summer 2006 until the natural rockfall on 14 August 2011 (red curve). The black dashed rectangle shows the extent of zoom (d). Panel (d): zoom of (c) between 20 July and 14 August 2011. For (c) and (d), the crises periods are outlined in orange.

sliding plane (F1, Fig. 2a and b, Fabre et al., 2013) striking $10^{\circ} \mathrm{N}, 53-61^{\circ} \mathrm{SE}$, while the bedding (S0) strikes $15^{\circ} \mathrm{N}$ and dips $45^{\circ} \mathrm{W}$ inwards (Table 1). Two families of fractures (F2 and F3) striking $70^{\circ} \mathrm{N}$ and $125^{\circ} \mathrm{N}$ were identified in the rock mass, with dips ranging from $80^{\circ} \mathrm{S}$ to vertical and $70^{\circ} \mathrm{N}$ to vertical, respectively. These discontinuities divide the column into many compartments, with the five larger of them reaching 200 to $2000 \mathrm{~m}^{3}$.

A geotechnical study conducted in 2004 showed that the Ripaillère hamlet (70 inhabitants) was directly threatened by potential rockfalls (Fig. 1a). Consequently, four extensometers and one tiltmeter were installed in summer 2006 to monitor the movements of the rock column. The measurements were continuously recorded and transmitted to an alert center at the $S A G E$ engineering office, which was in charge of the monitoring. In 2007, a ditch and a $9 \mathrm{~m}$ high by $300 \mathrm{~m}$ long earthen barrier were built up at the toe of the slope to protect the hamlet (grey patch in Fig. 1a). From 2006 to 2011, the extensometer installed in the lower part of the unstable column (E1, Fig. 2c) exhibited a steady displacement trend disrupted by some sharp rises, which were sometimes associated with small rockfall events. Following a period of heavy rainfalls $(130 \mathrm{~mm}$ over 9 days), a strong acceleration in displacement occurred between 22 and 28 July 2011 (Fig. 2c and d) with a velocity reaching $12 \mathrm{~mm} \mathrm{day}^{-1}$ before decreasing to $3 \mathrm{~mm} \mathrm{day}^{-1}$. However, between 7 and 13 August 2011, centimetric daily opening rates were once again reached with peaks close to $50 \mathrm{~mm} \mathrm{day}^{-1}$ on 13 August 2011. In the evening of the same day, authorities decided to preventively evacuate the hamlet. After an additional $30 \mathrm{~mm}$ displacement, a rockfall occurred at 02:30 UTC on $14 \mathrm{Au}-$ gust.
Table 1. Mean discontinuity orientation revealed by field (left column) and stereoscopic (right column) stereographic analyses.

\begin{tabular}{rrrrr}
\hline & \multicolumn{2}{c}{ Field analysis } & \multicolumn{2}{c}{ Stereoscopic analysis } \\
\hline & Strike $\left(^{\circ}\right)$ & Dip $\left(^{\circ}\right)$ & Strike $\left(^{\circ}\right)$ & Dip $\left(^{\circ}\right)$ \\
\hline S0 & $15 \mathrm{~N}$ & $45 \mathrm{~W}$ & $05 \mathrm{~N}$ & $30 \mathrm{~W}$ \\
F1 & $10 \mathrm{~N}$ & $53-61 \mathrm{SE}$ & $0 \mathrm{~N}$ & $60 \mathrm{E}$ \\
F2 & $70 \mathrm{~N}$ & $80-90 \mathrm{~S}$ & $87 \mathrm{~N}$ & $80 \mathrm{~S}$ \\
F3 & $125 \mathrm{~N}$ & $70-90 \mathrm{~N}$ & - & - \\
\hline
\end{tabular}

Only the $2000 \mathrm{~m}^{3}$ lower part of the column (demarcated with the dashed blue line, Fig. 2a and b) detached from the cliff and fell freely about $100 \mathrm{~m}$. Although most of the fallen mass was quickly deposited on the upper part of the slope, some approximately $15 \mathrm{~m}$ size blocks $\left(3\right.$ to $10 \mathrm{~m}^{3}$ ) propagated down the slope and were trapped in the ditch (Fig. 3d) after a run-out of $800 \mathrm{~m}$. The $2700 \mathrm{~m}^{3}$ upper compartment of the rock column (circled with the red dashed line in Fig. 2a and b) remained attached to the cliff. Owing to its low residual stability, the decision was taken to blast it. An additional $60 \mathrm{~m}$ long, flexible rockfall barrier was built at the northern extremity of the earthen barrier to extend the protection area (orange dash in Fig. 1a). Seismometers, video and photographic cameras were deployed in the area to record the artificially triggered rockfall. The blasting, undertaken by $\mathrm{Hy}$ drokarst company, occurred on 13 December 2011. 


\section{The artificially triggered rockfall}

\subsection{Description}

The remaining $2700 \mathrm{~m}^{3}$ unstable compartment (delineated with the red dashed line, Fig. 2a and b) was blasted on 13 December 2011 at 02:01:55 UTC, using $400 \mathrm{~kg}$ of explosives. As seen in Fig. 3a, the size of the blasted blocks strongly varies, from centimetric to metric scale. The largest blocks are located at the bottom of the compartment owing to a larger spacing between the blasting boreholes. From video clips, several phases of the rockfall could be identified and time-referenced (Fig. 3e). The blasted volume (Fig. 1b, spot 1, Fig. 3a) free-fell for 3 to $6 \mathrm{~s}$ before impacting the ground at the toe of the cliff (spot 2) and the top of the rocky scree (spot 3) about $1 \mathrm{~s}$ later. Smaller blocks dropped continuously from the cliff for about $30 \mathrm{~s}$. Simultaneously, most of the fallen rock mass settled rapidly on the upper part of the slope (rocky scree), generating a dense aerosol. Only a few large blocks propagated downwards across the forest (spot 4 in Fig. 1b), bouncing on the ground and felling trees. Seven meter-size blocks $\left(0.8\right.$ to $\left.12 \mathrm{~m}^{3}\right)$ reached the toe of the slope and were stopped by the ditch-earthen barrier system (spot 5 in Figs. 1b and 3d). One of them (block 6 in Fig. 3d) broke into two pieces when impacting the upper rock wall of the earthen barrier (Fig. 3c), about $45 \mathrm{~s}$ after the initial blast. Another block propagated further north in the slope (Fig. 3b), and ended in the flexible rockfall barrier (orange line in Fig. 1a). There was no sign of movement on the videos later than $90 \mathrm{~s}$ after the blast.

\subsection{Instrumentation}

A permanent seismic array (STM, Fig. 1a) located about $2.5 \mathrm{~km}$ southeast from the site recorded both the natural and the provoked rockfalls. This array was made up of six vertical short-period $(2 \mathrm{~Hz})$ sensors with one three-component (3C) seismometer at the center. Two additional short-period 3C sensors ( $\mathrm{AC} 1$ and $\mathrm{AC} 2$ ); two 6-channel, vertical sensors arrays (AN1 and AN2) and one 48-channel, $4.5 \mathrm{~Hz}$ vertical geophone array (CLE) were also deployed at the toe of the slope, to record the provoked rockfall (see location in Fig. 1a).

Photographs of the cliff were taken both before and after the provoked event from spots P1 and P2 (Fig. 1a), in order to carry out photogrammetric analysis (Poropat, 2001). A Canon EOS 5D Mark II digital camera with 21.1 megapixel resolution was used in combination with an Electro Focus $135 \mathrm{~mm} \mathrm{f} / 2 \mathrm{~L}$ Ultra Sonic Motor lens. Despite the large distance to the rock cliff (more than $1000 \mathrm{~m}$ ), it provided good sharpness, contrast and color rendition. A laser range finder was used to pin control points on the rock cliff for georeferencing the photographs.

A Canon EOS 500D digital camera with a $58 \mathrm{~mm}$ lens was installed at M1 (Fig. 1a) to shoot the whole propaga- tion of the blasting event, providing 25 frames per second, $1920 \times 1080$ pixel videos. In addition, one pair of similar digital cameras was installed about $40 \mathrm{~m}$ lower in altitude to get the trajectories of the fallen blocks (M2 and M3, Fig. 1a). The positions of all the instruments were determined by GPS.

Aerial lidar acquisitions were conducted both before and after the provoked event to obtain a high-resolution DSM (digital surface model) of the site. The first scan was conducted by Sintegra company on 29 September 2011 with a Riegl 2-D laser scan LMS-Q560 brought together with an inertial measurement unit (IMU) IXSEA and a dual-frequency GNSS receiver. The scan after the blast was acquired on 27 April 2012, using Hélimap System composed of a Riegl 2-D laser scan, a Hasselblad digital camera, an IMAR IMU and a dual-frequency GNSS receiver.

\subsection{Volume estimation}

The volume of the artificially triggered rock compartment was estimated using the aerial lidar scans and photographic images. lidar point clouds of the site area $\left(0.7 \mathrm{~km}^{2}\right)$ acquired before and after the provoked rockfall were treated using 3DReshaper software (www.technodigit.com). The points corresponding to the ground and cliff surface were kept, filtering points with low reflectivity coefficient (reflections on the vegetation) and manually rejecting aberrant points. The 2.4 million point large cloud was meshed with 469611 triangles. The blasted volume was determined by subtracting the DSM before (dark grey) and after the blast (light grey, Fig. 4a), leading to a $2570 \mathrm{~m}^{3}$ estimation. Two close views of the blasted column are shown in Fig. $4 \mathrm{~b}$ and c.

Detailed 3-D images were also obtained by processing stereographic pairs of photographs using Sirovision software (CSIRO, 2010a), and were georeferenced within the local coordinate system using control points on the rock slope. Two photographs of the same slope were taken at a distance close to $1000 \mathrm{~m}$. The cameras were positioned to obtain a baseline ratio between camera positions and the distance to the face of $1: 7$ or $1: 6$. Adjusting the 3-D images collected before (dark grey) and after (light grey) the blast, the volume difference and the displacement variation into the selected area are computed (Fig. 4d and e). The potential accuracy of the method given the equipment used in this study equates to the resolution of the range measurement at $150 \mathrm{~m}$, i.e., $5 \mathrm{~mm}$ for a displacement within the 2-D image of 1 pixel if the baseline is $1: 7$ (e.g., Poropat, 2006, Wolter et al., 2013). In optimum conditions (i.e., plane accuracy), the corresponding precision of the range measurement is approximately $3 \mathrm{~cm}$. However, the final model precision is more controlled by the accuracy of the georeferencing procedure than by the predicted photogrammetric precision stated above.

In the present case, with a distance of $1000 \mathrm{~m}$, the accuracy of the laser range was found to be close to $1 \mathrm{~m}$, leading to a precision of the 3-D georeferenced image close to the meter as well. The blasted volume was estimated at $2380 \mathrm{~m}^{3}$, 

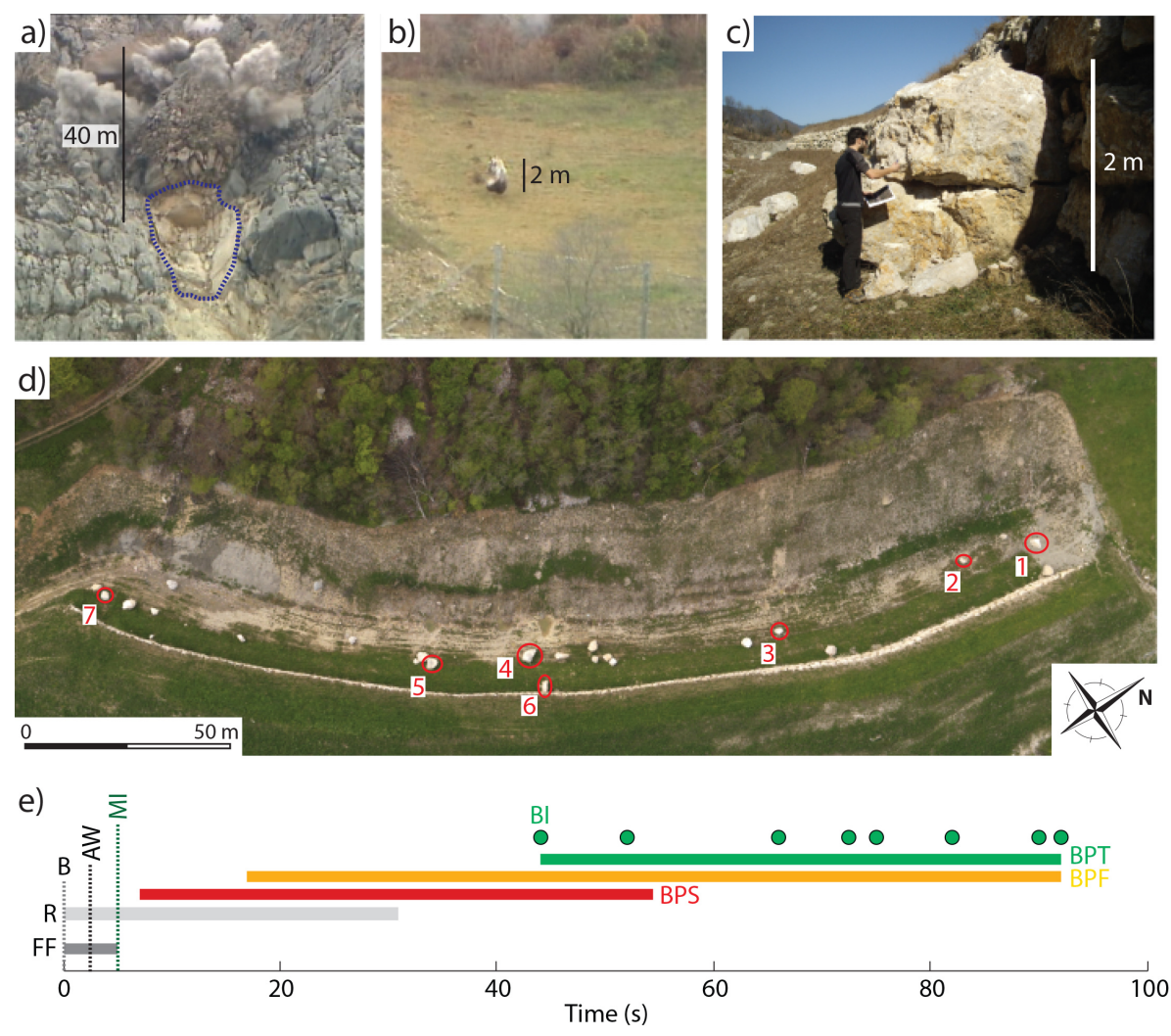

Figure 3. Pictures of the different phases of the blasting event. Panel (a): initiation phase. Picture of the unstable remaining $2600 \mathrm{~m}^{3}$ just after its blasting. The blue dashed line shows the footprint of the previous natural rockfall. Panel (b): propagation phase. Picture of a $3 \mathrm{~m}^{3}$ isolated block that propagated down the slope into the flexible rockfall barrier, visible at the bottom right. Panel (c): deposit phase. Picture of block 6 (cf. Fig. 3d) that split into two parts when impacting the rock-reinforced uphill side of the earthen barrier. Panel (d): deposit phase. Picture taken on 10 May 2012, after the natural and provoked rockfalls. The 15 blocks from the natural event are not numbered, with volumes ranging from 3 to $10 \mathrm{~m}^{3}$. The blocks generated by the provoked event are circled in red and numbered from 1 to 7, with volumes of 3, 0.8 , 4, 12, 9, 9 and $4 \mathrm{~m}^{3}$, respectively. Panel (e): chronology of the provoked rockfall derived from the video clips. From the left to the right: blast (B), free fall (FF), air wave (AW), main mass impact (MI), rocks falling from the cliff (R), block propagation in the scree (BPS), in the forest (BPF), at the toe of the slope (BPT) and block impacts in the ditch-earthen barrier (BI).

which is consistent with the volumes estimated by the consulting company $\operatorname{SAGE}\left(2700 \mathrm{~m}^{3}\right)$ and determined from lidar data $\left(2570 \mathrm{~m}^{3}\right)$. In this case, the aerial lidar provided a more complete topography than the photogrammetric technique because it could have access to the backside of the hanging block (see Fig. 2), which was not visible from the places where the pictures were taken. However, the photogrammetric technique offers the advantage of being much less expensive and more flexible.

\subsection{Discontinuity pattern}

Structural features of the cliff were extracted from the 3-D digital image taken after the provoked rockfall, using the Sirojoint software (CSIRO, 2010b). The planes to process for discontinuity orientation characterization are manually selected (colored areas in Fig. 5a) and the corresponding poles of each facet are shown by colored triangles on a stereographic diagram using a Wulff lower hemisphere projec- tion (Fig. 5b). Three sets of discontinuities were identified, and the average pole (square marker) and average plane (circle line) for each family are drawn in Fig. $5 b$ and listed in Table 1 . The bedding (S0, in green) strikes $353-11^{\circ} \mathrm{N}$ with $19-53^{\circ} \mathrm{W}$ inward dipping (mean $05^{\circ} \mathrm{N}, 30^{\circ} \mathrm{W}$ ), while the two fracture sets F1 (blue) and F2 are oriented $322-24^{\circ} \mathrm{N}$, with a dip of $53-73^{\circ} \mathrm{E}$ (mean orientation: $0^{\circ} \mathrm{N}, 60^{\circ} \mathrm{E}$ ) and $84-93^{\circ} \mathrm{N}$, with a dip of $77-86^{\circ} \mathrm{S}$ (mean orientation: $87^{\circ} \mathrm{N}$, $80^{\circ} \mathrm{S}$ ), respectively. Despite the metric resolution of these measurements, they are in good accordance with the structural analysis from the consulting company $S A G E$ (see Table 1 for comparison), which supports the reliability of the photogrammetric data. However, the fracture set F3 observed on field on the outcrops was not identified by the photogrammetric analysis. The limiting factors appear to be the resolution of the 3-D images and their manual processing, potentially leading to less accurate or fragmentary structural information. Nevertheless, the photogrammetric technique 
a)

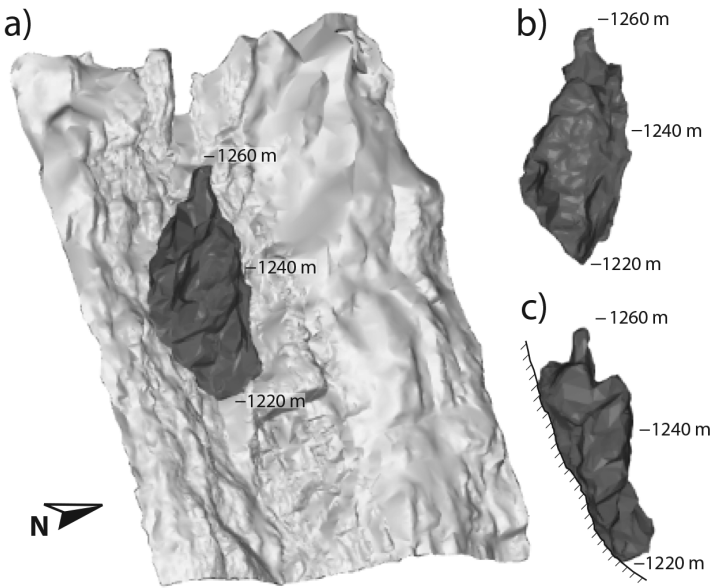

d)

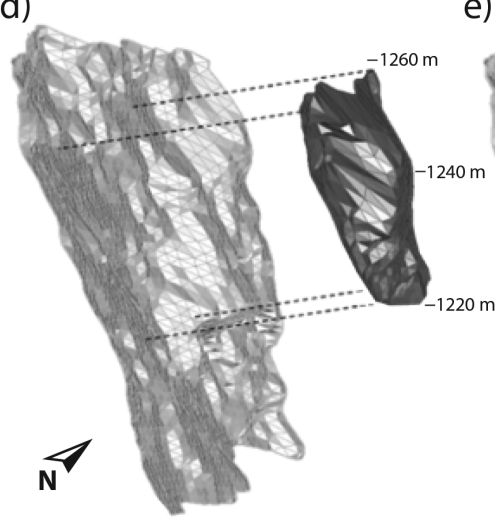

e)

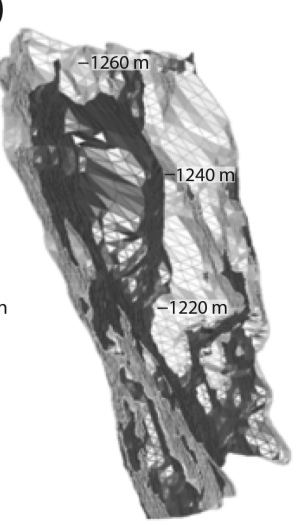

Figure 4. Panel (a): Discrete element method (DEM) before and after the blasting (in dark and light grey, respectively). Views of the unstable compartment (b) from east to west and (c) from south to north with the elevation shown by the black marks. The hatched line draws the cliff section in (c). Panel (d): 3-D images collected before (dark grey) and after (light grey) the blasting event. Panel (e): Sirovision model with superimposition of the 3-D images for volume determination.

showed its ability of retrieving the main discontinuity pattern of the cliff even from such remote viewpoint, over $1 \mathrm{~km}$ in this case (see also Sturzenegger and Stead, 2009).

\section{Seismic signal analysis and event identification}

Figure 6 shows the seismograms and spectrograms of the vertical component recorded by seismic station STM $(2.5 \mathrm{~km}$ away) for both the natural (a) and artificially triggered (b) rockfalls. While the volume estimated for the second event $\left(2570 \mathrm{~m}^{3}\right)$ is slightly larger than for the first one $\left(2000 \mathrm{~m}^{3}\right)$, the peak amplitude of the seismograms and the signal duration $(\sim 100 \mathrm{~s})$ are similar for the two events. The envelope of the first signal is smoother (Fig. 6a), with a progressive rise in amplitude. The highest amplitude is observed about $10 \mathrm{~s}$ after the first wave arrival, and then the ampli-

tude decreases and remains roughly constant for $50 \mathrm{~s}$ with some seismic pulses. For the triggered event (Fig. 6b), there is an impulsive start followed by a spike $7 \mathrm{~s}$ later owing to the acoustic waves generated by the explosion. For the time period between 15 and $40 \mathrm{~s}$, the signal amplitude is slightly smaller than for the natural event. There is a clear peak at $45 \mathrm{~s}$ after the blast, synchronously with the first blocks impacting the toe of the slope. Both natural and artificially triggered event spectrograms show an irregular envelope (Fig. 6c and d), with some energetic seismic pulses that probably result from multiple sources and the propagation of different waves (Deparis et al., 2008; Dammeier, 2011). Most of the energy lies below $20 \mathrm{~Hz}$, in good agreement with the range tenths of $\mathrm{Hz}$ to dozens of $\mathrm{Hz}$ observed for other rockfalls (Dammeier et al., 2011; Hibert et al., 2011). Excluding the acoustic waves, the main energetic phases in the signals are the ground impact following the free fall and later events which could correspond to impacts of rock blocks at the slope toe. This issue is discussed below by comparing close seismograms and the videos. Figure 7 shows the seismic signals and spectrograms of the vertical component recorded for the artificially triggered rockfall by stations $\mathrm{AC} 1(\mathrm{a}, \mathrm{c})$ and AC2 (b, d). The signal amplitude is generally larger for station $\mathrm{AC} 2$, which is located closer to the blast. The seismic phases are interpreted in light of the event sequence determined from video clips (Fig. 3e). Both signals show an impulsive start and high amplitudes for the first $2 \mathrm{~s}$ (arrow 1 in Fig. 7) associated with the blasting. The high-frequency acoustic wave arrives about $3 \mathrm{~s}$ after the blast (arrow 2), followed by the large impact of the fallen mass at the base of the cliff beginning about $3 \mathrm{~s}$ later (arrow 3 ). There is a clear decrease in signal amplitude for the time period between 15 and $30 \mathrm{~s}$ (arrow 4), when most of the rock mass gradually settles in the rocky scree, the latter acting probably as a mattress and attenuating the seismic waves transmitted into the ground. The amplitude then rises gradually from 30 to $45 \mathrm{~s}$ (arrow 5), especially on AC1 located at the toe of the slope. This probably results from seismic source movement, as the blocks propagate downwards and approach the sensors.

At station $\mathrm{AC} 1$, the largest amplitude in the seismogram is observed $45 \mathrm{~s}$ after the blast (arrow 6). It corresponds to block 6 that hit the uphill rock reinforced wall of the earthen barrier (Fig. 3d and c). This seismic peak is also visible at $\mathrm{AC} 2$, but is weaker due to greater source-sensor distance. Several pulses with large amplitudes (notably for AC2) occur from 60 to $90 \mathrm{~s}$ (arrow 7) and are associated with the late propagation of blocks along the slope, predominantly in its northern part. Finally, seismogram amplitudes for both sensors decrease rapidly for the time period after $90 \mathrm{~s}$, in good accordance with the videos. For the period after than $15 \mathrm{~s}$, spectrograms (Fig. 7c and d) show an overall triangular shape that has been commonly observed in rockfalls and snow avalanches (Suriñach et al., 2005; Vilajosana et al., 2008) and related to material propagation effects. The energy lies mainly in a frequency range between 1 and $50 \mathrm{~Hz}$, which 
a)

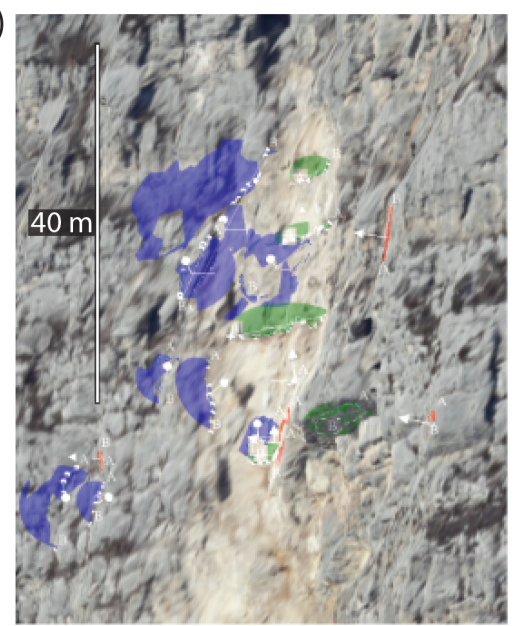

b)

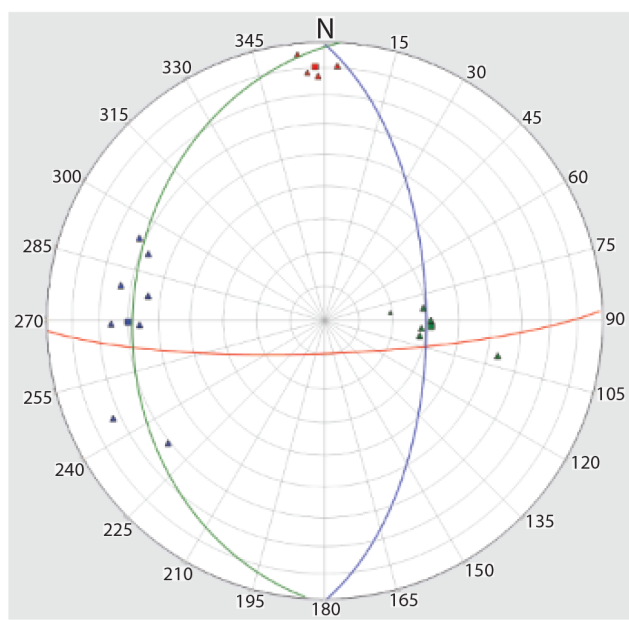

Figure 5. Panel (a): 3-D picture of the cliff after the provoked rockfall. The planes manually selected for discontinuity orientation characterization are shown with the colored areas, along with their respective normal vector (white arrow). The mean cliff plane strikes $15^{\circ} \mathrm{N}$. Panel (b): stereographic diagram of (a) using Wulff lower hemisphere projection. The pole of each facet is shown by a triangle, whereas the average pole is pointed out with a square marker. The average plane is drawn with a circle line. The bedding (S0, in green) as well as F1 (blue) and F2 (red) fracture sets are retrieved.
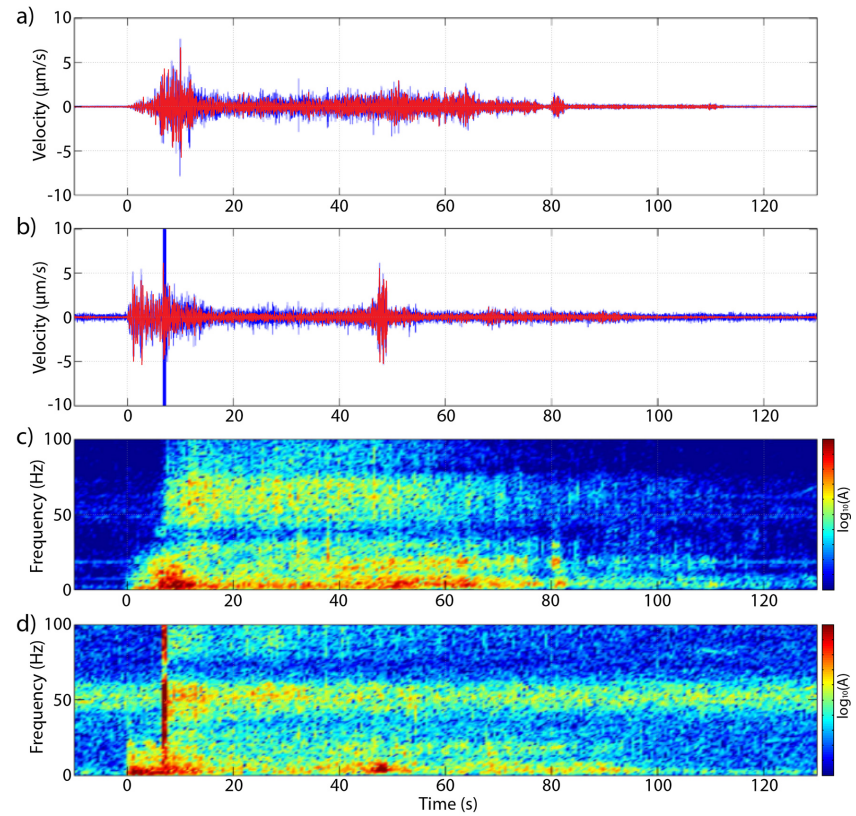

Figure 6. Seismograms (a, b, in blue) and spectrograms (c, d) of the vertical component seismic signals recorded by station STM for the natural $(\mathbf{a}, \mathbf{c})$ and artificially triggered $(\mathbf{b}, \mathbf{d})$ rockfalls. The seismograms filtered in the $1-20 \mathrm{~Hz}$ range for magnitude estimation are shown in red. Spectrograms are computed using a fast Fourier transform of 256 samples and are shown using the same logarithmic color scale for both events.
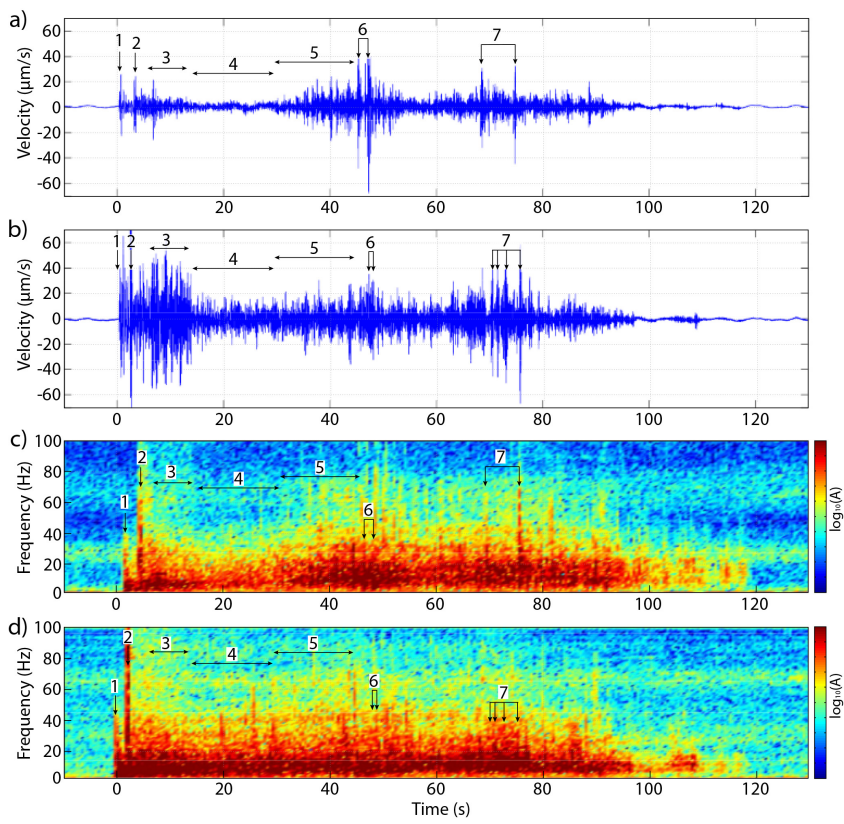

Figure 7. Seismograms $(\mathbf{a}, \mathbf{b})$ and spectrograms $(\mathbf{c}, \mathbf{d})$ of the vertical component seismic signals recorded by station $\mathrm{AC} 1(\mathbf{a}, \mathbf{c})$ and AC2 $(\mathbf{b}, \mathbf{d})$ for the artificially triggered rockfall. Spectrograms are computed using a fast Fourier transform of 256 samples and are shown using the same logarithmic color scale for both stations. 
is higher than that recorded by STM because of less attenuation at stations closer to the source. For the two main dominant phases, the energy mainly lies in the $1-20 \mathrm{~Hz}$ frequency range, with spectral peaks between 2 and $6 \mathrm{~Hz}$ (Fig. 7c and d).

\section{Event characterization and localization}

\subsection{Magnitude}

\subsubsection{Natural and provoked rockfalls}

The magnitude of the natural and provoked rockfalls was estimated from the peak amplitude of the seismic signals detected at seismic station STM, located about $2.5 \mathrm{~km}$ south from the blast. The relationship between distance, peak amplitude and magnitude proposed by Lacroix and Helmstetter (2011) for the Séchilienne rockslide (located $20 \mathrm{~km}$ away) was employed. This relation was calibrated using magnitudes computed by SISMALP seismic network for regional earthquakes (http://sismalp.obs.ujf-grenoble.fr). The shots performed at Séchilienne for tomographic purposes were also used to better constrain this relationship for short distances. The magnitude is computed from the peak amplitude $A$ (in $\mu \mathrm{m} \mathrm{s}^{-1}$ ) of the signal filtered between 1 and $20 \mathrm{~Hz}$ (Fig. 6) and from the distance $d$ (in $\mathrm{km}$ ) to the source using the relationship $M=\log _{10}\left[A \exp \left(d / d_{0}\right) / d^{n}\right]$, with $n=0.95$ and $d_{0}=151 \mathrm{~km}$. The magnitude is 1.14 for the natural event and 1.05 for the triggered one, considering the peak amplitude generated by the impact of the mass on the ground $(t \approx 6$ to $10 \mathrm{~s}$, Fig. 6). These values are in good agreement with values of magnitude and volumes reported by Deparis et al. (2008) for other rockfalls in the French Alps. Applying the magnitude $(M)$ - seismic energy $\left(E_{\mathrm{S}}\right)$ relationship $\log _{10} E_{\mathrm{s}}=1.5 M+4.8$ (Kanamori, 1977) gives $E_{\mathrm{s}}=3.2 \times$ $10^{6}$ and $2.4 \times 10^{6} \mathrm{~J}$ for the natural and provoked rockfall, respectively. Assuming that the potential energy $E_{\mathrm{p}}$ of the fallen mass is fully converted into kinetic energy $E_{\mathrm{k}}$ during free fall, the ratios between the seismic energy released by the impact and the kinetic energy are $8 \times 10^{-4}$ and $4.7 \times 10^{-4}$ for the natural and provoked events, respectively. These values lie in the conversion ratio range commonly found in the literature (see introduction). Magnitude was also computed for the impact of block 6 into the earthen barrier $(t \approx 45 \mathrm{~s}$, Fig. 6) from the provoked rockfall seismogram recorded at station STM, leading to $M=0.98$. Applying the same magnitude - seismic energy relationship yields $E_{\mathrm{s}}=1.9 \times 10^{6} \mathrm{~J}$.

\subsubsection{Subsidiary rockfall}

The seismic network remained in operation for 3 days after the blast. The continuous seismic signal recorded by stations AN1 and AN2 were analyzed using the automatic detection method of Helmstetter and Garambois (2010) which is based on the spectrogram of the signal. During this time, one sub-
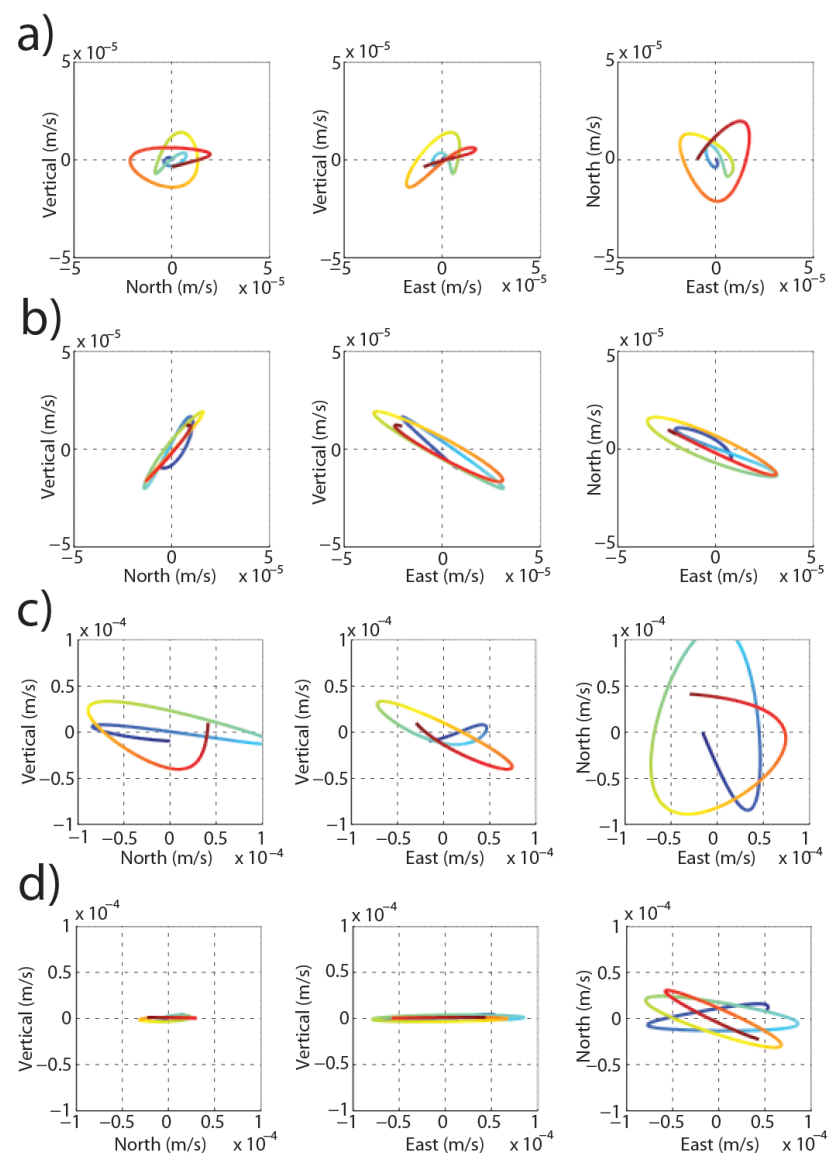

Figure 8. Polarization analysis using the $3 \mathrm{C}$ sensors $\mathrm{AC} 1$ (a and $\mathbf{b}$ ) and AC2 (c and d) for both the impact at the toe of the cliff (a and $\mathbf{c}$ ) and the impact of block 6 into the earthen barrier (b and d). The particle motion is shown by the continuous line, whose color indicates the time (from blue to red). The axes show the motion velocity in the vertical, north or east direction.

sidiary rockfall was detected which occurred on 13 December 2011 at 23:50 UTC, i.e., $9 \mathrm{~h}$ after the shot. The seismic signal amplitude of this event (ground impact) at station AN1 was 140 times smaller than the provoked rockfall. Under the hypothesis that these two events originate from the same area of the cliff, we can estimate the volume of the second event from the magnitude of the seismic signal. Assuming that the seismic moment is proportional to the rockfall volume and that the seismic moment scales with magnitude $M$ as $10^{1.5 M}$ (Hanks and Kanamori, 1979), the volume of the second event is estimated to about $1.5 \mathrm{~m}^{3}$. This value agrees with the field observations made on the cliff scar by the consulting company (SAGE, personal communication, 2012). These results indicate the ability of seismic arrays for monitoring rockfalls and estimating the fallen volumes. 


\subsection{Polarization study for the main identified phases}

For the provoked rockfall, polarization analysis was conducted on the seismograms in order to identify the nature of the waves (compressional, shear or surface waves) recorded by the $3 \mathrm{C}$ sensors. The ground impact following free fall and the impact of block 6 into the earthen barrier, which are the two main energetic phases in the signal, were studied. Signals from $\mathrm{AC} 1$ and $\mathrm{AC} 2$ were windowed and band-pass filtered in the $2-6 \mathrm{~Hz}$ range, where most of the energy lies (see Fig. 7c and d). Figure 8 shows the particle motion at the two stations $\mathrm{AC} 1(\mathrm{a}, \mathrm{b})$ and $\mathrm{AC} 2(\mathrm{~b}, \mathrm{c})$. The signal generated by the impact of the mass on the ground after free fall $(a, c)$ shows a complex pattern with no specific polarization regarding the visualization plane, probably due to multiple impacts and complex seismic paths. In contrast, the signals generated by the impact into the earthen barrier $(b, d)$ exhibit strong linear ground motion at both sensors.

At AC2, the movement is purely horizontal and predominantly oriented along the east-west direction, whereas there is a slight vertical component of motion at AC1 with vibration striking ESE-WNW. These linear, mainly horizontal ground motions appear perpendicular to the source-sensor path in the horizontal plane (Fig. 9a). Simulations of wave propagation are carried out in Sect. 6 to better understand the origin of such polarization pattern.

\subsection{Location of seismic sources}

The beam-forming method of Lacroix and Helmstetter (2011) is applied to locate the seismic source. This method has been developed for locating seismic sources when the first arrival is difficult to pick with precision and allows monitoring the position of a moving source over time. In this method, the position of the source and the seismic wave velocities are inverted by maximizing the temporal correlation between all traces after shifting each trace by the travel time. The inversion starts with a $100 \mathrm{~m}$ cell size grid search and an initial seismic wave velocity. For each grid point, the travel times between this point and all sensors are computed. The traces are then shifted by this travel time and the average weighted correlation between all couples of traces is computed. The weight associated with each couple of traces decreases with the distance between sensors to give more weight to nearby sensors with a better inter-trace correlation. The weights were also tuned so that each seismic antenna has the same weight, otherwise the results would be controlled mainly by station CLE which has 48 channels compared to 6 for stations AN1 and AN2. The grid point with the largest correlation is then used as the initial point for a simplex optimization of inter-trace correlation. Although the seismic velocity is likely very heterogeneous, a uniform velocity is assumed for simplicity and fixed to $2000 \mathrm{~m} \mathrm{~s}^{-1}$ for seismic waves and $340 \mathrm{~m} \mathrm{~s}^{-1}$ for acoustic waves.
This method was applied to different time windows, starting with using the first $2.5 \mathrm{~s}$ of the seismic signals (explosive blast) filtered in the range $3-20 \mathrm{~Hz}$. The inverted apparent velocity is $1750 \mathrm{~m} \mathrm{~s}^{-1}$, corresponding probably to $S$ waves or surface waves, which are the most energetic. The estimated source is located $110 \mathrm{~m}$ to the west of the actual location. The location uncertainty can be estimated from the area where the correlation is within $5 \%$ of the peak correlation (Lacroix and Helmstetter, 2011). In this case, the uncertainty is $555 \mathrm{~m}$ (blue contour in Fig. 9a). This limited resolution is due to the weak correlation between signals and to heterogeneities of seismic wave velocities. The same method was then applied to acoustic waves produced by the explosion. The signal was selected in the time window between 2.65 and $3.85 \mathrm{~s}$ after the blast and filtered in the range $20-80 \mathrm{~Hz}$ to remove lowerfrequency $P$ and $S$ waves. We assume an initial velocity of $340 \mathrm{~m} \mathrm{~s}^{-1}$ and obtain an inverted value of $337 \mathrm{~m} \mathrm{~s}^{-1}$. In this case, the estimated location is very close to the actual one, the location error is of $17 \mathrm{~m}$ and the estimated uncertainty is $32 \mathrm{~m}$ (magenta contour in Fig. 9a). The accuracy is much better for acoustic waves because the air velocity is much more uniform, even if the correlation quality between traces is much smaller for acoustic waves than for seismic waves (the weighted average inter-trace correlation is 0.8 for seismic waves and 0.37 for acoustic waves).

We then used the beam-forming method to monitor the source position over the full duration of the seismic signal, using a sliding time window of $1 \mathrm{~s}$. The velocity was fixed to $1750 \mathrm{~m} \mathrm{~s}^{-1}$, and the signal was filtered between 3 and $20 \mathrm{~Hz}$. Because of the limited resolution of the method, the source location was imposed along the mean path of the rockfall (dashed black line in Fig. 9a). For each time window, the point that maximizes the inter-trace correlation is computed and the estimated sources are shown as colored points in Fig. 9a. Figure 9b presents the distance $d$ along the path from the blast point as a function of time (top), with a simplified chronology of the provoked rockfall phases from videos (bottom). During the first $30 \mathrm{~s}$ of signal, several sources were located very close to the explosion $(d \sim 0 \mathrm{~m})$. They were probably generated by the blast (B, Fig. $9 \mathrm{~b})$ and by the blocks continuously falling from the cliff $(\mathrm{R})$. Then $(15-55 \mathrm{~s})$, the blast point-source distance linearly increases with time from $d=0$ to approximately $1000 \mathrm{~m}$, with an average velocity of $22 \mathrm{~m} \mathrm{~s}^{-1}$. This phase corresponds to the block propagation in the scree (BPS) and in the forest (BPF) spotted on the videos. After this $\sim 55 \mathrm{~s}$ time limit, the source location is relatively stable with some scattering. It matches the time when the $7 \mathrm{~m}$ size blocks arrived at the toe of the slope (BPT) and were trapped in the ditch-earthen barrier. Although there were still blocks propagating on the upper part of the slope, the seismic signal is likely dominated by the propagation front which is closer to the seismic sensors. 
a)

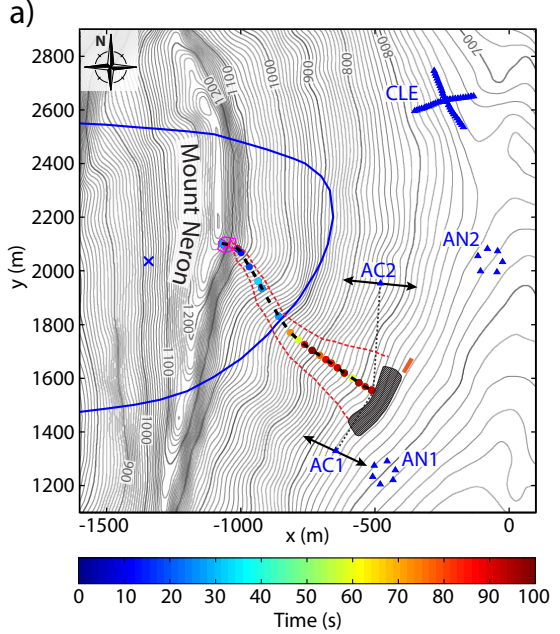

b)

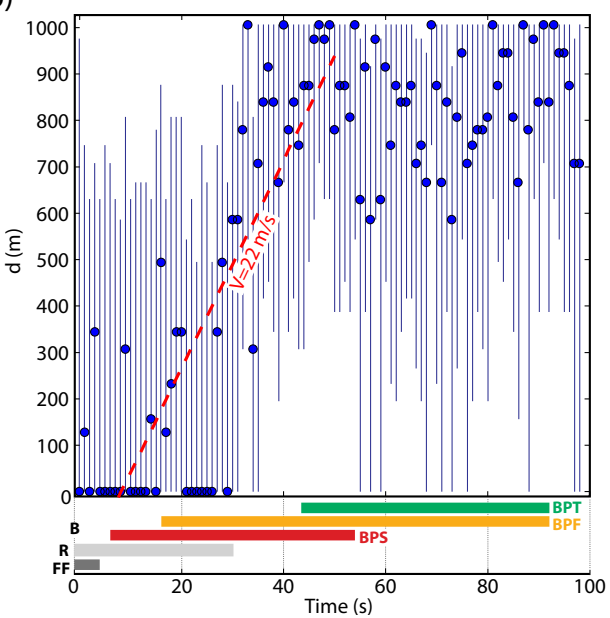

Figure 9. Panel (a): seismic source location estimated using different waves and time windows. Source location with the beam-forming method applied either to the first $2.5 \mathrm{~s}$ of the signal (blue cross) or to the acoustic waves produced by the explosion (magenta cross). The location uncertainties for the beam-forming method are estimated by the area where the mean inter-trace correlation is larger than $95 \%$ of its peak value (blue and magenta contours). The colored circles illustrate the propagation of the source using a $1 \mathrm{~s}$ long sliding time window, constrained on the mean rockfall path (black dashed line). Time ranges from the blast (in blue) until $100 \mathrm{~s}$ later (dark red). Similarly to Fig. 1a, blue triangles show the seismometers, the hatched grey contour indicates the earthen barrier and the red dashed line represents the area of provoked rockfall propagation. The black double arrows show the direction of ground motion polarization for the impact of block 6 into the earthen barrier (see Fig. 8b and d). The grey dotted line points out the source-sensor path. Panel (b): top, estimated location of the seismic signal source (blue points) computed every second since the blast. The source is imposed to be along the main propagation path shown as a black dashed line in (a). The vertical blue lines are error bars (points along path with correlation larger than $95 \%$ of the maximum value). The distance (vertical axis) is measured from the blast location, along the main propagation path. The red line is a linear fit for the first $50 \mathrm{~s}$ of the signal giving an average propagation velocity of $22 \mathrm{~m} \mathrm{~s}^{-1}$. Bottom: simplified chronology of the provoked rockfall from the video clips (see Fig. 3e). From the left to the right: blast (B), free fall (FF), rocks falling from the cliff (R), block propagation in the scree (BPS), in the forest (BPF) and at the toe of the slope (BPT).

\subsection{Estimation of the block and mass velocities from the videos}

The video clips were processed in order to assess the block velocities during the fall and propagation phases using two different approaches. The image processing software 7-D (Vacher et al., 1999) was employed to calculate the displacement field in a given window (Fig. 10) from one frame to the next, for the first $17 \mathrm{~s}$ of the video.

The software applies a pattern recognition algorithm based on image correlation technics. Knowing the real pixel size and the sampling frequency of the frames, the displacement is transformed into velocity. The block velocities are spatially averaged, as the block density in each pixel is not taken into account. The intrinsic processing error was estimated by analyzing the histogram of the displacements calculated on zones that were supposedly stable. The histogram (not shown here) displays a log-normal shape with a mean of 0.5 pixels and a standard deviation of 0.5 pixels. Only displacements larger than one pixel between two successive frames are considered in the following. The displacement field (magnified 10 times in pixel size) at three different times (1,3 and $11 \mathrm{~s})$ is superimposed with the corresponding photographs in Fig. 10a. The mean velocity amplitude in the vertical direc- tion $\left(V_{y}\right.$, solid red line) and the mean velocity norm $\left(V_{\mathrm{n}}\right.$, solid blue line) in the photograph plane are displayed in Fig. 10b. After the initial sharp acceleration related to the blast, the two curves tend to remain parallel, indicating that $V_{x}$ (in the horizontal direction) slightly oscillates between 10 and $15 \mathrm{~m} \mathrm{~s}^{-1}$. In contrast, $V_{y}$ drops for the period between 0.5 and $1 \mathrm{~s}$ before increasing again rapidly for $2 \mathrm{~s}$ (Fig. 10a, left), following a constant acceleration. The velocity drop probably results from the contribution of the blocks projected upward, while the rise fits well with the free fall hypothesis $\left(V_{y}=g t\right.$, black dashed line in Fig. 10b) until the main mass impacts the toe of the cliff for the period between 3 and $6 \mathrm{~s}$ after the blast (Fig. 10a, center). Afterwards, the mean vertical velocity in the given window settles at a constant value of about $12 \mathrm{~m} \mathrm{~s}^{-1}$. As visible in the right picture in Fig. 10a, the dust generated by the rockfall, however, produces artifacts in the image correlation, affecting the later time periods and $x$ direction velocities as the wind laterally pushed the smoke.

Stereographic videos of the blasting were also used to determine the 3-D trajectories of the blocks individually propagating down the slope, with the aim of quantifying their translational and rotational velocities. The planar coordinates of specific blocks were extracted manually with ImageJ soft- 
Table 2. Comparison of average propagation velocities for different types of rock instabilities, determined from video and/or seismic analysis. The mean slope angle and the difference in altitude are given between the initial position of the unstable mass and the toe of the deposit area.

\begin{tabular}{lllccccc}
\hline \multirow{2}{*}{ Type } & Name & Rock type & $\begin{array}{c}\text { Mean } \\
\text { slope } \\
\text { angle }\left(^{\circ}\right)\end{array}$ & $\begin{array}{c}\text { Difference } \\
\text { in } \\
\text { altitude }(\mathrm{m})\end{array}$ & $\begin{array}{c}\text { Max punctual } \\
\text { speed } \\
\left(\mathrm{m} \mathrm{s}^{-1}\right)\end{array}$ & $\begin{array}{c}\text { Mean } \\
\text { velocity } \\
\left(\mathrm{m} \mathrm{s}^{-1}\right)\end{array}$ & Reference \\
\hline \multirow{2}{*}{$\begin{array}{l}\text { Rock } \\
\text { avalanches }\end{array}$} & Thurwieser & $\begin{array}{l}\text { Limestone } \\
\text { and dolostone }\end{array}$ & 17 & $\sim 1300$ & $60-65$ & $36-38$ & Sosio et al. (2008) \\
$\left(>10^{5} \mathrm{~m}^{3}\right)$ & Mount & $\begin{array}{l}\text { Sandstone } \\
\text { and siltstone }\end{array}$ & 22 & $\sim 1300$ & - & 80 & McSaveney (2002) \\
\cline { 2 - 8 } & Mount Cook & $\begin{array}{l}\text { Graywacke } \\
\text { and argillite }\end{array}$ & 32 & $\sim 2600$ & - & $55-60$ & McSaveney (2002) \\
\hline
\end{tabular}

\begin{tabular}{lllllll}
\hline $\begin{array}{l}\text { Rockfalls } \\
\left(10^{3}-10^{5} \mathrm{~m}^{3}\right)\end{array}$ & Mount Néron & Limestone & 40 & 550 & & \\
Free fall & & & & - & $30^{1}$ & This work \\
$\begin{array}{l}\text { Block } \\
\text { propagation }\end{array}$ & & & & $12-281,3$ & $20^{2}$ & - \\
\hline $\begin{array}{l}\text { Isolated } \\
\text { block falls } \\
\left(<10^{3} \mathrm{~m}^{3}\right)\end{array}$ & - & - & 34 & 30 & $20-251,4$ & - \\
\hline
\end{tabular}

${ }^{1}$ Derived from video processing (Sect. 3.4); ${ }^{2}$ obtained by seismic source location technique (Sect. 3.3); ${ }^{3}$ at mid-slope; ${ }^{4}$ at the slope toe (see Fig. 1a).

ware (http://rsb.info.nih.gov) from each frame of the video clips simultaneously by the M2 and M3 cameras (Fig. 1a). The use of 12 reference points pinned in each frame allowed us to reconstruct the 3-D trajectory of particular blocks. The conversion was optimized by minimizing the error between the measured and calculated point positions. However, the poor definition of the videos which cover the entire slope and the dense vegetation prevented a detailed tracking of most of the blocks (Fig. 10c). Consequently, velocity values were only determined for block 6 , the trajectory of which is visible in both videos (Fig. 10d). Two specific bounces occurring at mid-slope (940 and $900 \mathrm{~m}$ in altitude, grey stars in Fig. 1a) and showing long free-flight phases were studied in more detail. The block translational speeds before and after the bounces lie in the range $12-14.5$ and $22-28 \mathrm{~m} \mathrm{~s}^{-1}$, respectively (Table 2). At the toe of the slope, the translational and rotational velocities of block 6 were estimated to 20 to $25 \mathrm{~m} \mathrm{~s}^{-1}$ and to about $10 \mathrm{rad} \mathrm{s}^{-1}$, respectively, before the impact into the earthen barrier. Considering the $9 \mathrm{~m}^{3}$ block as a homogeneous sphere with a density of $2500 \mathrm{~kg} \mathrm{~m}^{-3}$, the total kinetic energy $\left(E_{\mathrm{c}}\right)$ is about $6 \times 10^{6} \mathrm{~J}$ prior to the impact.

The ratio between the seismic energy released by the impact $\left(E_{\mathrm{S}}\right.$, Sect. 3.1) and the above-computed kinetic energy before impact $\left(E_{\mathrm{k}}\right)$ is about $0.3,3$ orders of magnitude larger than the ratios $\left(5 \times 10^{-4}\right.$ and $\left.8 \times 10^{-4}\right)$ obtained for the two Néron events. This strong difference could result from (1) the strong nonlinear behavior in the soil deposits (scree overlying marly layer) at the cliff toe, (2) the free fall hypothesis of a rigid mass, which is probably incorrect because of disintegration and impacts of blocks on the cliff face or (3) the progressive fall of the mass for a few seconds, which makes the seismic energy transfer not instantaneous. These three effects tend to underestimate the ratio $E_{\mathrm{S}} / E_{\mathrm{k}}$. In contrast, the effect of the rigid rock-reinforced barrier at the slope toe, on which the block 6 broke, could explain the high conversion ratio from mechanical to seismic energy.

Translational velocities at mid-slope derived from video analysis $\left(12-28 \mathrm{~m} \mathrm{~s}^{-1}\right)$ are of the same order of magnitude as those derived from seismic source location $\left(22 \mathrm{~m} \mathrm{~s}^{-1}\right.$, Sect. 3.3). Even so, the seismic source location technique provides an average location of all the seismic sources over a given time window which may be related to the dynamics of the propagation front along the slope, whereas the video analysis focuses on the dynamics of one single fast propagating block. These propagation velocities are compared with the results of other studies using image analysis and seismic signal processing (Table 2). Such data are quite rare for rockfalls of medium size like the one studied and the comparison was extended to rock avalanches (volume $>10^{5} \mathrm{~m}^{3}$ ) and isolated blocks. With the largest fallen volumes and the greatest difference in altitude, rock avalanches show the greatest propagation velocities (36-80 $\mathrm{m} \mathrm{s}^{-1}$ mean velocity), even if the mean slope angle over the entire path is moderate. On the contrary, the two studies concerning isolated rock blocks deal with human-triggered, block drop field experiments on steep slopes, but with small differences in eleva- 
a)

b)
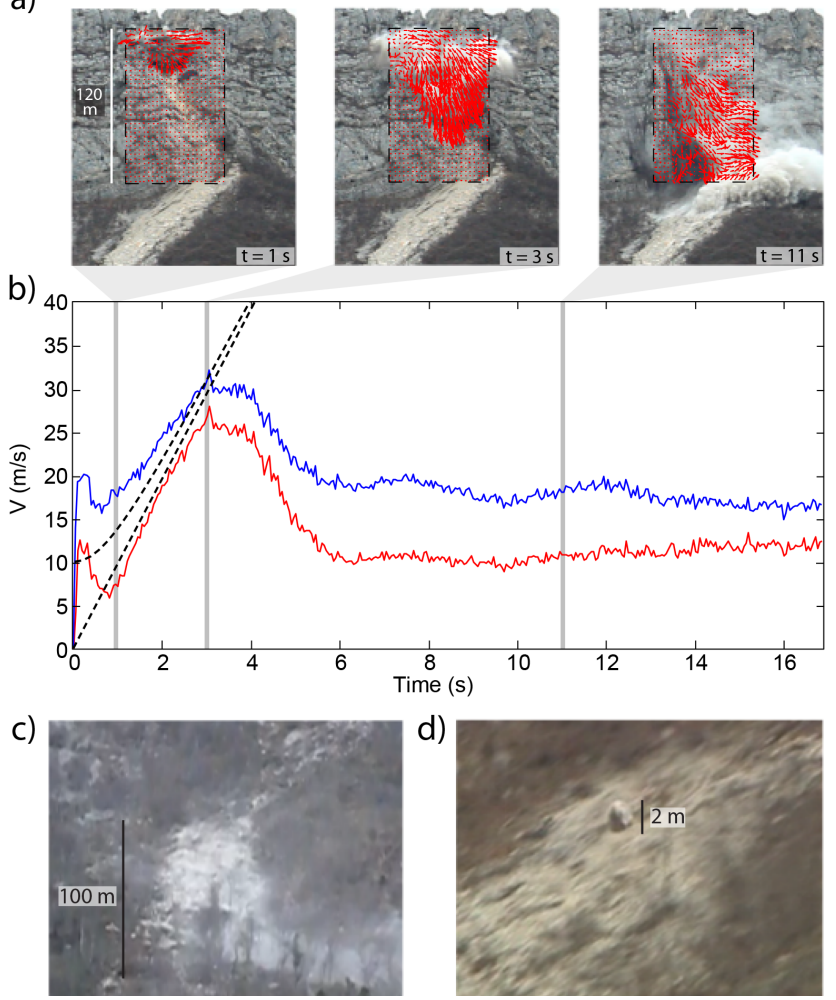

Figure 10. Panel (a): images of the artificially triggered rockfall taken at three different times $\left(t_{1}, t_{2}\right.$ and $\left.t_{3}\right)$ with displacement field (magnified 10 times in pixel size, red arrows) superimposed. Panel (b): mean vertical $\left(V_{y}\right.$, in red) and norm $\left(V_{\mathrm{n}}\right.$, in blue) velocities of the blocks retrieved from image correlation analysis (solid lines) and from numerical discrete element simulation (dashed lines). The free fall equations along the vertical direction $\left(V_{y}=g t\right)$ and norm $\left(V_{\mathrm{n}}=\left[(g t)^{2}+V_{0}^{2}\right]^{1 / 2}\right)$ are shown by the black dashed line, where $g=9.81 \mathrm{~m} \mathrm{~s}^{-2}$ is the gravitational acceleration, $V_{0}=10 \mathrm{~m} \mathrm{~s}^{-1}$ is the initial horizontal velocity due to the blast, and $t$ is the time. The times corresponding to the pictures in (a) are marked with the vertical grey lines. Panel (c): TIFF image extracted from the $1920 \times$ 1080 pixels videos showing the toe of the scree deposits and the upper part of the slope (labeled 3 and 4, respectively, in Fig. 1b). Panel (d): zoom-in of block 6 during propagation.

tion. Thus, maximum block velocity reaches about $30 \mathrm{~m} \mathrm{~s}^{-1}$, and the mean velocity ranges around $12-15 \mathrm{~m} \mathrm{~s}^{-1}$. Mount Néron mid-size rockfall is characterized by a relatively steep slope (about $40^{\circ}$ on average) with an intermediate difference in altitude $(550 \mathrm{~m})$. Three different stages of propagation can be defined during the rockfall. At the early stage, the falling rock mass followed the free-fall equation with maximal mass velocity of $\sim 30 \mathrm{~m} \mathrm{~s}^{-1}$. After the impact at the toe of the cliff, the fallen volume behaved as a rock mass with moderate propagation speed $\left(\sim 20 \mathrm{~m} \mathrm{~s}^{-1}\right.$ on average over the whole event) and settles rapidly. Several isolated blocks emerge from this mass, and propagate down the slope. Velocities of $12-28 \mathrm{~m} \mathrm{~s}^{-1}$ at mid-slope are reported for one single
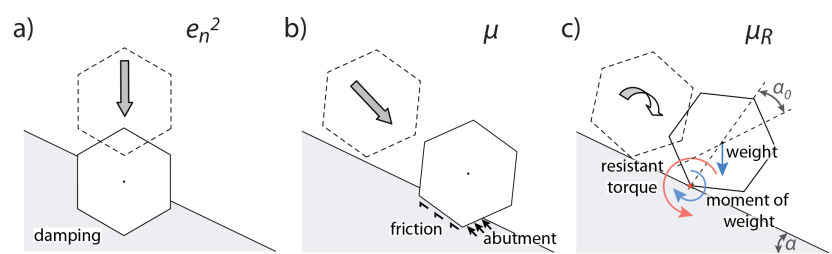

Figure 11. Schematic sketch illustrating the normal $\left(e_{n}^{2}, \mathbf{a}\right)$ and tangential $(\mu, \mathbf{b})$ restitution coefficients, as well as the resistive rolling coefficient $\left(\mu_{\mathrm{R}}, \mathbf{c}\right)$. The grey arrow shows the direction of motion. The resistant torque introduced in the contact law at the contact point is shown in red in (c).

block, which reaches a maximal velocity of $20-25 \mathrm{~m} \mathrm{~s}^{-1}$ at the toe of the slope. These values measured during the Mount Néron rockfall are bracketed by the values found in the literature $\left(15-80 \mathrm{~m} \mathrm{~s}^{-1}\right)$. The interesting feature is that one block $\left(9 \mathrm{~m}^{3}\right)$ generated a signal as energetic as the mass impacting the ground after the free-fall sequence: this is probably due to the collision at high speed (translational and rotational) in the highly compacted, rock-reinforced earthen barrier.

\section{Rockfall propagation modeling}

The artificially triggered rockfall propagation was simulated using the discrete element method (DEM) based on rigid body dynamics. The objective of this simulation was to compare numerical propagation velocities with experimental data. Within the simulations, the motion of each block is powered by gravity and the model accounts for both translation and rotation.

This numerical model takes account of realistic block shapes and specific contact laws which are able to represent the main dissipation phenomena at the contact-rebound point. It was validated by comparison with experimental results from Manzella and Labiouse (2009) involving a granular flow of small bricks on an inclined plane.

The normal and tangential contact force laws between discrete elements (Richefeu et al., 2012) are controlled by two dissipation coefficients: $e_{n}^{2}$ and $\mu$. The parameter $e_{n}^{2}$ reflects the amount of energy restored in the perpendicular direction to the impact plane (Fig. 11a). In the case of a vertical drop of a block on a horizontal plane, this coefficient is the ratio between the height of rebound of the particle and the height of the initial drop. A value of 1 corresponds to a perfectly elastic collision, and a value close to 0 refers a strongly dissipative contact. The parameter $\mu$ is a coefficient which allows one to introduce the energy dissipation in the tangential direction to the contact plane. For a contact between rocks and soft soil, this coefficient incorporates abutment force and shear strength of the soil of the impacted area in addition to frictional forces (Fig. 11b).

Different values and definitions of the restitution coefficients are proposed in the literature, leading to a wide range 

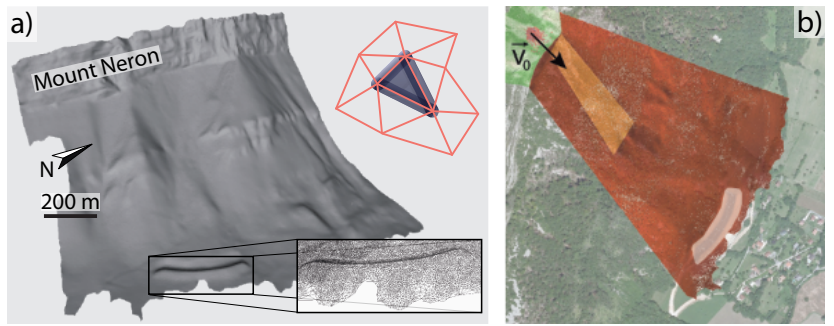

Figure 12. Panel (a): the digital surface model is built by joining basic forms (top right corner) on the mesh of the lidar DSM. A detailed view is shown for the earthen barrier mesh (bottom right corner). Panel (b): spatial zoning of the site, depending on the type of terrain: solid rock (green), rocky scree (orange), soft ground with trees (red) and earthen barrier (light grey). The initial velocity $V_{0}$ given to the blocks is shown by the black arrow.

of possible parameters (Heidenreich, 2004). It was shown that on the experiment scale, the type of experiments performed and the nature of the soil have a great influence on the values of the restitution parameters obtained. According to these works, high values of the normal restitution coefficient $\left(e_{n}^{2}\right)$ need to be considered for block impacts involving hard surface, paving or bedrock (0.6-0.15 respectively) and small values for impacts on soft soil slopes $(0.2-0.1)$. The abutment forces integrated into the tangential restitution coefficient $(\mu)$ strongly depend on the blocks' shape, the nature of the soil, the impact intensity and angle. For impacts involving hard surface and bricks, the tangential restitution coefficient corresponds to the dynamic friction angle (Richefeu et al., 2012), whereas values greater than the friction angle need to be considered for impacts on soft soil. The tangential restitution coefficient remains poorly constrained owing to a lack of an experimental, representative rock block rebound data set.

To adapt the numerical model to the resistive phenomenon occurring during the rotation of angular blocks on a soft soil, a resistive moment was introduced by means of a resistive rolling coefficient $\left(\mu_{\mathrm{R}}\right)$. Without rolling resistance, the moment of the weight force with respect to the contact point on the slope (function of the block shape) acts as a source of rotational motion and cannot be compensated by the contact force itself, since the latter generates no moment at the contact point (Fig. 11c). The rolling resistant torque $\boldsymbol{C}$, inversely proportional to the angular velocity of the block $\omega$, was therefore defined in the model and scaled with the normal force $f_{\mathrm{n}}$ (i.e., with the ground indentation):

$\boldsymbol{C}=-\min \left(\gamma_{\mathrm{R}}\|\boldsymbol{\omega}\|, \mu_{\mathrm{R}} \ell f_{\mathrm{n}}\right) \frac{\boldsymbol{\omega}}{\|\boldsymbol{\omega}\|}$,

where $\gamma_{\mathrm{R}}$ is a parameter of regularization and $\mu_{\mathrm{R}}$ is the coefficient of rolling friction. The latter dimensionally scales with a length and plays a role similar to the friction coefficient in classical Coulomb law. It is physically interpreted as the amount of soil punching that happens during a collision
Table 3. Dissipation coefficients along the normal direction $\left(e_{n}^{2}\right)$, tangential direction $(\mu)$ and rolling friction $\left(\mu_{\mathrm{R}}\right)$ defined for (i) block-solid rock (including another block), (ii) block-rocky scree, (iii) block-soft ground with trees and (iv) block-earthen barrier contacts.

\begin{tabular}{lrrrr}
\hline & $\begin{array}{r}\text { Solid } \\
\text { rock }\end{array}$ & $\begin{array}{r}\text { Rocky } \\
\text { scree }\end{array}$ & $\begin{array}{r}\text { Soft ground } \\
\text { with trees }\end{array}$ & $\begin{array}{r}\text { Earthen } \\
\text { barrier }\end{array}$ \\
\hline$e_{n}^{2}$ & 0.30 & 0.05 & 0.01 & 0.001 \\
$\mu$ & 0.50 & 1.00 & 0.20 & 1.20 \\
$\mu_{\mathrm{R}}$ & 0.00 & 0.20 & 0.10 & 0.90 \\
\hline
\end{tabular}

expressed as a portion of the mean size $\lambda$ of the blocks. The minimum value of $\mu_{\mathrm{R}}$ necessary to stop the rolling movement of a block under its own weight is a function of the slope angle $(\alpha)$ and the block geometry $\left(\alpha_{0}\right)$, and can be expressed by the following expression (see also Fig. 11c):

$\mu_{\mathrm{R} 0}=\sin \left(\alpha-\alpha_{0}\right) / \cos (\alpha)$.

Values greater than $\mu_{\mathrm{R} 0}$ slow down the propagation of a single block on a slope.

The unstable rock column is modeled by an amount of randomly arranged blocks with an apparent volume of about $2500 \mathrm{~m}^{3}$ (Fig. 13b). Each rock block is considered as a discrete element of regular polyhedral shape with rounded edges and vertices. Block unitary volumes are uniformly distributed between 1 and $9 \mathrm{~m}^{3}$, matching the size of blocks that propagated down to the slope toe in the real event. Smaller blocks were not included in the simulations for saving computation time as the video clips suggest that they settled rapidly.

The topography of the slope corresponds to a coarse version of the lidar DSM (triangular elements of $10 \mathrm{~m}$ in characteristic size) to speed up the computation. The edges and vertices of each facet have also been rounded (Fig. 12a). This allows unambiguous definition of the contact directions between the blocks and the terrain or in-between the blocks. Due to the great influence of the soil nature on the restitution coefficients, the DSM was zoned into four different areas according to the type of terrain: solid rock, rocky scree, soft ground with trees and earthen barrier material (Fig. 12b). For each type of zone, the dissipation coefficients $\left(e_{n}^{2}, \mu\right.$ and $\mu_{\mathrm{R}}$, Table 3) were defined from a set of values from the literature (Heidenreich, 2004). A value of $\mu=1$ was retained for the impact between blocks and rocky scree in order to take into account the tangential interaction and the pushing of the rocky blocks during impact. This set of parameters was improved by trial and error until the simulated rockfall time propagation behaved closely to the real one, i.e., with most of the mass $(\sim 80 \%)$ being deposited on the upper half of the slope (rocky scree) and presence of blocks stopped by the ditch-earthen barrier (Figs. 13c and 14c).

The triggering of the rockfall consisted of setting an initial horizontal velocity $\left(V_{0}\right)$ to the blocks to mimic the initial 

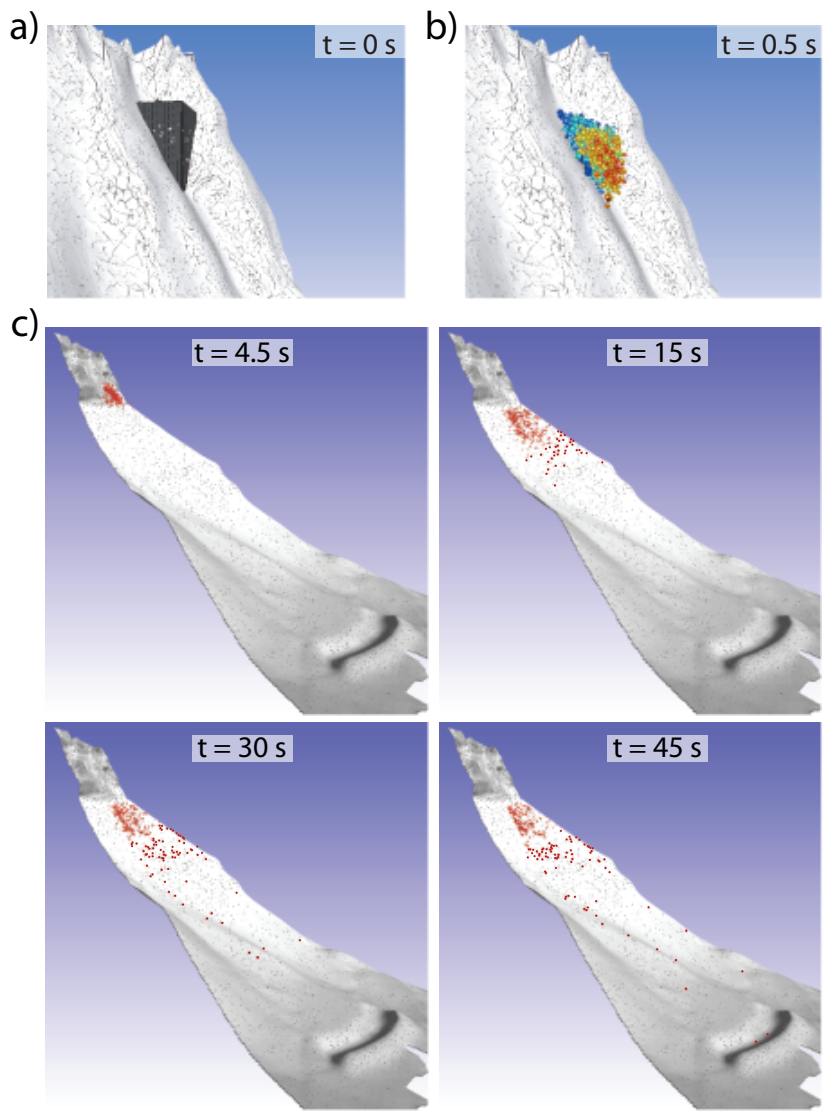

Figure 13. Panel (a): picture of the zone with the unstable mass confined in an apparent $2500 \mathrm{~m}^{3}$ volume $(t=0 \mathrm{~s})$. Panel (b): artificial triggering of the rockfall simulation after wall removing and initial velocity push $(t=0.5 \mathrm{~s})$. Panel (c):screenshots of a simulation taken at four different times. Rocks blocks are shown in red on the light grey DSM.

blasting energy (Fig. 13a and b). $V_{0}$ was set at $10 \mathrm{~m} \mathrm{~s}^{-1}$ outwards and normal to the cliff (Fig. 12b), which is the value measured by digital image correlation (Sect. 3.4). Right after the triggering, the blocks remained together as a whole during free fall until they impacted the toe of the cliff (Fig. 13c).

The numerical translational $\left(V_{\mathrm{t}}\right)$ and rotational $(\omega)$ block velocities are shown as a function of the distance to the blast $d$ in Fig. 14a and b, as well as the final mass distribution on the slope in Fig. 14c. The $30-35 \mathrm{~m} \mathrm{~s}^{-1}$ maximum mean block velocity is reached at the toe of the cliff $(d \approx 100 \mathrm{~m})$ during the free-fall phase, very similarly to what observed at $t \approx 4 \mathrm{~s}$ with image correlation (Fig. 10b). At the same distance, the mean rotational speed peaks at $10 \mathrm{rad} \mathrm{s}^{-1}$. Most of the blocks then slow down rapidly, due to ground impact. Between 150 and $450 \mathrm{~m}$ (rocky scree), the mean translational and rotational speeds remain low (about $5 \mathrm{~m} \mathrm{~s}^{-1}$ and $5 \mathrm{rad} \mathrm{s}^{-1}$ ) because most of the blocks stop there (see final mass distribution in Fig. 14c). The velocity range is yet wide, with some blocks speeding up to $V_{\mathrm{t}} \approx 60 \mathrm{~m} \mathrm{~s}^{-1}$ and $\omega \geq 50 \mathrm{rad} \mathrm{s}^{-1}$, as observed in the real case. Most of the blocks with large unitary volume propagate further down and stop in the soft ground area with trees, between $d=450 \mathrm{~m}$ and $900 \mathrm{~m}$ (Fig. 14c). The mean translational and rotational speeds increase slowly and irregularly, as the few blocks still propagating speed up and bounce on the ground. The translational velocities studied in Sect. 4.4 (black stars at $d=380$ and $410 \mathrm{~m}$, Fig. 14a) lie in the fastest $25 \%$ numerical blocks range, probably because the video analysis focuses on large, fast-propagating blocks.

The average seismic source velocity of $22 \mathrm{~m} \mathrm{~s}^{-1}$ determined using seismic source location (see Sect. 4.3) is compatible with the numerical block propagation (thick grey dashed line in Fig. 14a) and reflects the global, averaged kinematics of the seismogenic processes occurring in the rockfall. At the toe of the slope $(d \geq 900 \mathrm{~m})$, translational and rotational speeds lie in the $10-35 \mathrm{~m} \mathrm{~s}^{-1}$ (mean $20 \mathrm{~m} \mathrm{~s}^{-1}$ ) and $7-23 \mathrm{rad} \mathrm{s}^{-1}$ ranges (mean $14 \mathrm{rad} \mathrm{s}^{-1}$ ), respectively. These values are in good accordance with the video analysis of block 6 before its collision with the earthen barrier (see Sect. 4.4), which yielded $V_{\mathrm{t}} \approx 20-25 \mathrm{~m} \mathrm{~s}^{-1}$ and $\omega \approx 10 \mathrm{rad} \mathrm{s}^{-1}$ (black stars, Fig. 14a and b). At the end of the simulation (about $80 \mathrm{~s}$ ), six blocks have reached the ditchearthen barrier, with the first impact into the earthen barrier occurring at $t \approx 40 \mathrm{~s}$, which is similar to the real case.

The modeling of the Néron artificially triggered rockfall showed that the discrete element technique can provide valuable insights into rockfall kinematics once appropriately calibrated. In particular, numerical translational and rotational block velocities agreed well with seismic and video observations, with mean values ranging from 5 to $35 \mathrm{~m} \mathrm{~s}^{-1}$ and 0 to $14 \mathrm{rad} \mathrm{s}^{-1}$, respectively. Such simulations, which provide full information about the volume, velocity and trajectory of each individual block, could be of critical help to design protection structures. They need, however, to be applied to other case studies and gain forecasting ability through reliable, a priori determination of the restitution coefficients.

\section{Seismic modeling of a block impact}

The seismic wave field generated by impact of block 6 (Fig. 3d) into the ditch-earthen barrier was numerically simulated to explain the discriminative feature pattern of polarization seen in Sect. 3.2. The 3-D finite element model (FEM) Comsol software (www.comsol.com) was used for dynamic elastic simulations. A two-layer model was designed (Fig. 15a) according to the results from a refraction seismic survey. The top soft layer was found to be $5 \mathrm{~m}$ thick, with $P$ and $S$ wave velocities of 700 and $400 \mathrm{~m} \mathrm{~s}^{-1}$, respectively. A higher velocity layer $\left(V_{\mathrm{P}}=2450 \mathrm{~m} \mathrm{~s}^{-1}\right.$ and $V_{\mathrm{S}}=800 \mathrm{~m} \mathrm{~s}^{-1}$ ) was detected below, probably corresponding to the marly bedrock. Densities in the two layers were fixed to 1900 and $2500 \mathrm{~kg} \mathrm{~m}^{-3}$, from top to bottom. The impact was modeled by a unitary load applied to the model 


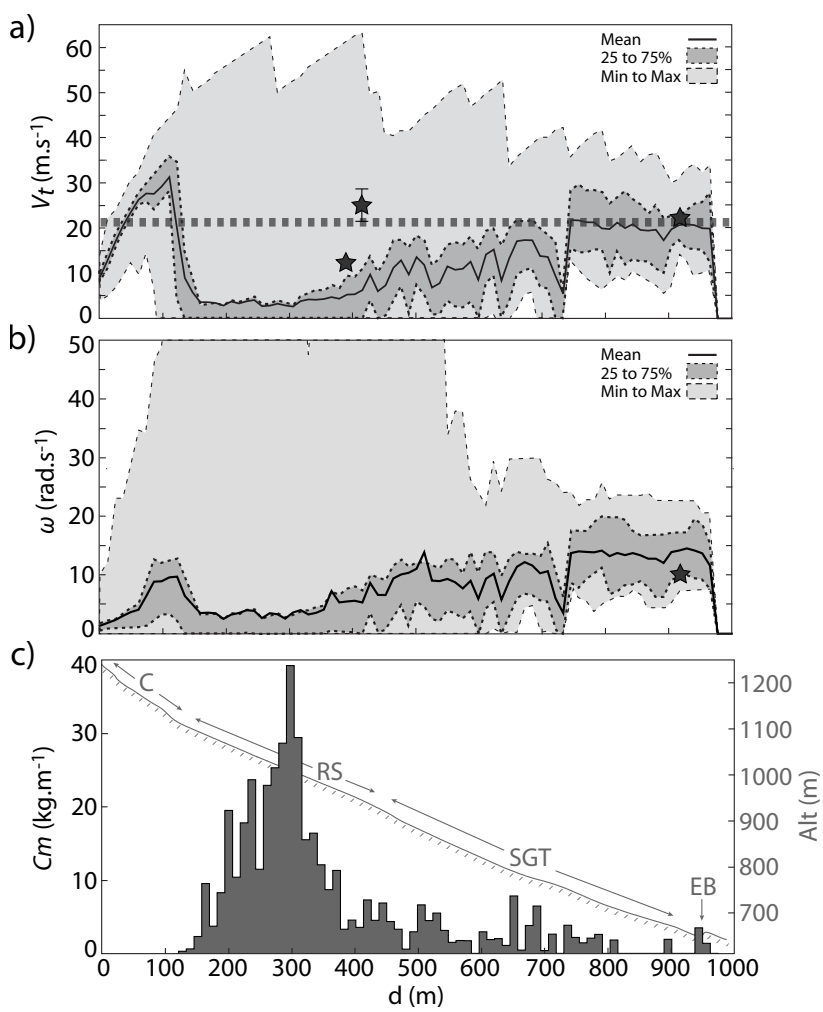

Figure 14. Numerical modeling of the rockfall propagation. Panel (a): translational velocity $V_{\mathrm{t}}$ as a function of the propagation distance $d$ from the blast. The mean value is shown as a black continuous line, the dark grey and light grey show the $25-75 \%$ and minmax intervals, respectively. The black stars point out the velocities derived from video analysis. The thick grey dashed line shows the seismic source mean velocity. Panel (b): rotational velocity $\omega$ as a function of the propagation distance $d$ from the blast. Same legend as (a). Panel (c): bar graph of the final mass distribution over distance $d$ from the blast. The cliff (C), rocky scree (RS), soft ground with trees (SGT) and earthen barrier (EB) are shown along the slope section (grey).

surface for $0.2 \mathrm{~s}$ and striking perpendicularly to the sourcesensor direction with $45^{\circ}$ inclination. Four $3 \mathrm{C}$ sensors (blue triangles in Fig. 15a) were setup along this same axis to study the wave field propagation, with source-sensor distance ranging from 0 to $250 \mathrm{~m}$. The medium was meshed with second-order tetrahedrons, with smaller elements setup along the source-sensor path to fulfill the FEM requirements for adequate spatial resolution of propagating waves (Bazant et al., 1978; Moser et al., 1999). The generalized-alpha, implicit time integration algorithm was used (Chung and Hulbert, 1993). The $5 \times 10^{-3}$ s time step provides accurate resolution for frequencies up to $10 \mathrm{~Hz}$ (ANSYS, 1992), and could be related to the time of propagation between two successive nodes in the mesh for the fastest wave of interest (Moser et al., 1999).

The radial (red), tangential (blue) and vertical (black) seismic signals computed at the four sensors, from the load point a)
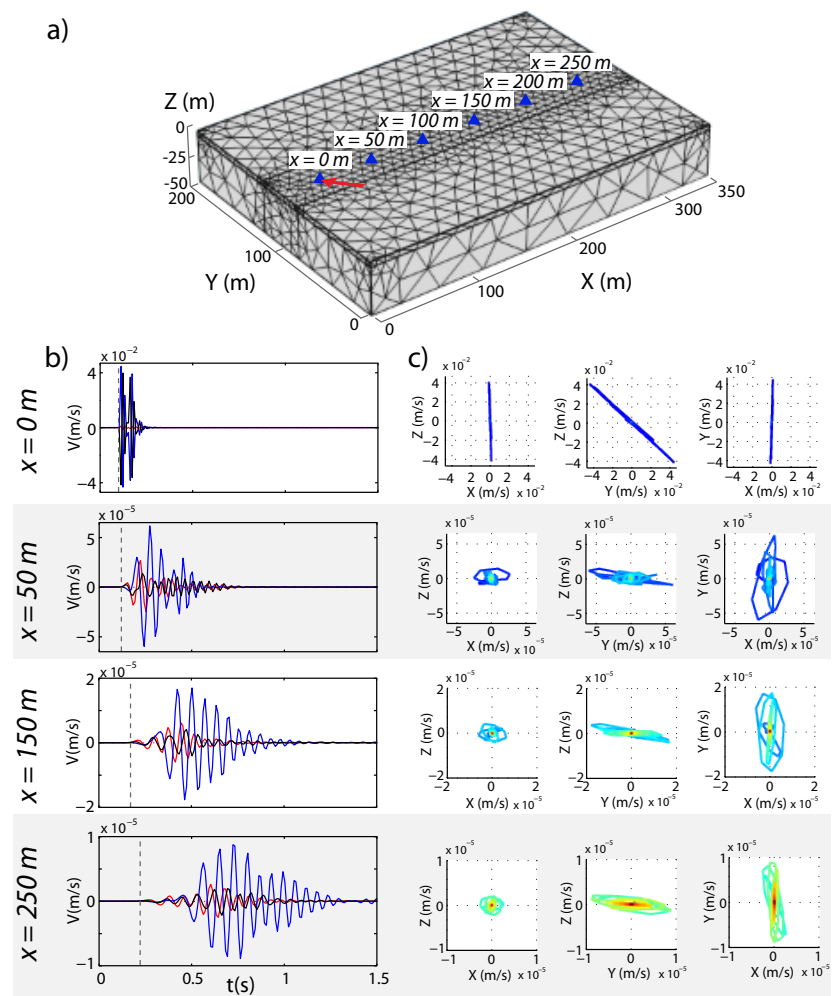

Figure 15. Numerical modeling of the impact of block 6 on the earthen barrier. Panel (a): tetrahedral mesh of the two-layer finite element model. The red arrow symbolizes the point load inclined at $45^{\circ}$ in the $Z-Y$ plane and blue triangles show the four velocity sensors setup along the $x$ axis. Panel (b): synthetic seismograms computed during $1.5 \mathrm{~s}$ at the four $3 \mathrm{C}$ sensors ranging from 0 to $250 \mathrm{~m}$ in distance $x$ to the source. Vertical ( $Z$, black), radial $(X$, red $)$ and tangential $(Y$, blue) component are presented. Panel (c): particle motions of the signals displayed in (b). The radialvertical ( $X Z$, top), tangential-vertical $(Y--Z$, center) and radialtangential $(X--Y$, bottom) planes are shown. Color scales with time, from blue $(t=0 \mathrm{~s})$ to red $(t=1.5 \mathrm{~s})$. Note that the amplitude scale depends on source-sensor distance in (b) and (c).

location $(x=0 \mathrm{~m})$ to the last sensor $(x=250 \mathrm{~m})$ over the first $1.5 \mathrm{~s}$ of simulation are presented in Fig. 15b. The corresponding particle motions are presented in the radial-vertical ( $X-Z$, top), tangential-vertical $(Y-Z$, center) and radialtangential $(X-Y$, bottom) planes in Fig. 15c. The seismograms exhibit waves propagating at different velocities. The first arrival (marked with grey dashed line in Fig. 15b) shows high velocity and low amplitude, and corresponds to the head wave refracted on the top of the marly bedrock. Then, the signal is dominated by slow and large amplitude waves corresponding to surface waves. The wavefield is dominated by the tangential component (Fig. 15b), with a maximal amplitude about 2 to 3 times greater than the others. The polarization in the tangential-vertical plane (Fig. 15c) exposes a $45^{\circ}$ dipping particle motion at load point location which rapidly flattens with distance, indicating the predominance of 
Love waves. In contrast, Rayleigh waves which appear in the radial-vertical plane are only little excited. Numerical particle motions can be compared with experimental motions related to the impact of block 6 into the earthen barrier. Both the numerical diagram at $x=250 \mathrm{~m}$ (Fig. 15b) and the experimental diagram at sensor AC1 (Fig. 8b), that have similar source-sensor distance, demonstrate clear, horizontal, transverse particle motions related to Love waves. Although simulations were not carried out for greater source-sensor distances for computation time reasons, the same numerical particle motion is likely to be observed at $\operatorname{AC} 2(x \approx 400 \mathrm{~m})$, in good accordance with the recorded, horizontal, transverse motion (Fig. 8d).

\section{Conclusions}

The medium-size artificially triggered rockfall of December 2011 at Mount Néron provided a unique opportunity to compare artificial to natural rockfalls regarding their respective propagation and seismic characteristics, using various ground and remote techniques. The following conclusions can be drawn from the present study. First, field survey, photogrammetric and aerial lidar surveys yielded consistent volume estimations for this event (from 2380 to $2700 \mathrm{~m}^{3}$ ). Although its resolution is lower, the low-cost ground photogrammetry technique has shown its potential for evaluating the volume and performing a structural analysis of the cliff, even with a ranging distance of $1 \mathrm{~km}$. Secondly, joint video and seismic data interpretation enabled the establishment of the relationship between provoked rockfall stages and seismic phases, particularly, signals related to the initial blast, to the ground impact of the mass, to its settlement on the upper part of the scree slope and to isolated block impacts were clearly identified. The two main energetic phases correspond respectively to the ground impact following the free fall and a $9 \mathrm{~m}^{3}$ block impacting the earthen barrier at the final slope toe. In contrast, the mass propagation along the scree slope generated little seismic energy. A simultaneous use of the image correlation and the seismic source location techniques provided the rockfall kinematics characterization. It was observed that maximal propagation speed was reached at the end of the free fall $\left(\sim 30 \mathrm{~m} \mathrm{~s}^{-1}\right)$ and the mass velocity abruptly dropped to about $20 \mathrm{~m} \mathrm{~s}^{-1}$ after the ground impact. From stereoscopic videos, the velocity of one isolated block ranged from 12 to $28 \mathrm{~m} \mathrm{~s}^{-1}$ at mid-slope, depending on the kinetic energy lost and gained during the propagation. Velocities ranging from 20 to $25 \mathrm{~m} \mathrm{~s}^{-1}$ for the translational mode and $10 \mathrm{rad} \mathrm{s}^{-1}$ for rotational mode were recorded at the slope toe. For the blocks impacting the protective earthen barrier, strong associated seismic signals $(M \approx 0.98)$ were recorded, resulting from a high conversion ratio from kinetic energy to induced seismic waves. These observations are of primary importance for correctly interpreting the seismic phases. Moreover, polarization analysis and modeling of the impact sequences showed surface waves dominating the wavefield.

The main features of the rockfall (free fall phase, major block settlement on the rocky scree area and propagation of isolated blocks down the slope) were numerically reproduced with the aim of calibrating a discrete element model. The free fall simulation agreed well with image correlation analysis and theoretical free fall equations, assuming initial horizontal block velocities induced by the blast. The propagation path of isolated blocks and the event duration were consistently reproduced, as well as the order of magnitude of translational and rotational velocities. The model predicted impact speeds comparable to the ones estimated from the videos, i.e., ranging from 10 to $35 \mathrm{~m} \mathrm{~s}^{-1}$ and 7 to $23 \mathrm{rad} \mathrm{s}^{-1}$. This case study provided a straightforward way to calibrate a set of dissipation coefficients which could be used for future works. These values yet need to be further constrained, for example by processing very high resolution videos of real events, tracking numerous block trajectories.

This study provided an exceptional opportunity to compare natural and provoked rockfalls of similar volumes (2000 and $2570 \mathrm{~m}^{3}$, respectively) occurring at the same location. Neglecting the initial blast and the associated acoustic wave, natural and provoked rockfalls generated comparable seismic signals (duration, peak amplitude, spectrograms), yielding close magnitude estimations $(M \approx 1.1)$. This supports that the source mechanism has little control on the global mass propagation. In contrast, the number of blocks reaching the ditch was higher for the natural event (15) than for the provoked one (7), suggesting a dramatic effect of blasting on the block size.

Acknowledgements. This work was partially funded by the Interreg project MASSA, the federal body VOR (Vulnérabilité des Ouvrages aux Risques) and the laboratory ISTerre. The used seismic instruments belong to the French national collection Sismob-RESIF.

Authors express gratitude to the municipality of Saint Martin le Vinoux and to the Préfecture de l'Isère for allowing the deployment of a scientific experiment in a restricted area. This work would not have been achieved without the help of many people during field work. We are especially grateful to Coralie Aubert, Simon Bayle, Nathalie Cotte, Glenn Cougoulat, Lionel Darras, Isabelle Doustebacqué, Mickael Langlais, Patrick Larizza, Sandrine Roussel, Julien Turpin, Jean Virieux, Marc Wathelet, Julie d'Amato and Lauren Ducret, as well as Arnaud Leone and Steven Cuervo, who also performed the image processing work.

\section{Edited by: T. Glade}

Reviewed by: three anonymous referees

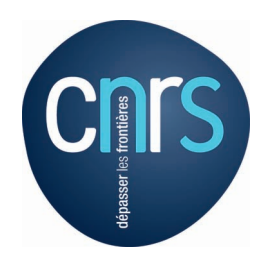

The publication of this article is financed by CNRS-INSU. 


\section{References}

Allstadt, K.: Extracting source characteristics and dynamics of the August 2010 Mount Meager Landslide from broadband seismograms, J. Geophys. Res.-Earth, 118, 1472-1490, doi:10.1002/jgrf.20110, 2013.

ANSYS user's manual for revision 5.0, Houston, TX, Swanson Analysis Systems, 1992.

Baillard, C., Crawford, W. C., Ballu, V., Hibert, C., and Mangeney, A.: An automatic Kurtosis-based $\mathrm{P}$ and $\mathrm{S}$ phase picker designed for local and regional seismic networks, B. Seism. Soc. Am., 104, 394-409, doi:10.1785/0120120347, 2013.

Banton, J., Villard, P., Jongmans, D., and Scavia, C.: Twodimensional discrete element models of debris avalanches: Parameterization and the reproducibility of experimental results, J. Geophys. Res., 114, F04013, doi:10.1029/2008JF001161, 2009.

Battaglia, J., Got, J.-L., and Okubo, P.: Location of long-period events below Kilauea Volcano using seismic amplitudes and accurate relative relocation, J. Geophys. Res., 108, ESE 2-1-2-16, doi:10.1029/2003JB002517, 2003.

Bazant, Z. P.: Spurious reflection of elastic waves in non-uniform finite element grids, Comput. Method. Appl. M., 16, 91-100, 1978

Biescas, B., Dufour, F., Furdada, G., Khazaradze, G., and Surinach, E.: Frequency content evolution of snow avalanche seismic signals, Surv. Geophys., 24, 447-464, doi:10.1023/B:GEOP.0000006076.38174.31, 2003.

Brodsky, E. E., Gordeev, E., and Kanamori H.: Landslide basal friction as measured by seismic waves, Geophys. Res. Lett., 30, 2236, doi:10.1029/2003GL018485, 2003.

Caplan-Auerbach, J. and Huggel, C.: Precursory seismicity associated with frequent, large ice avalanches on Iliamna volcano, Alaska, USA, J. Glaciol., 53, 128-140, 2007.

Chung, J. and Hulbert, G. M.: A time integration algorithm for structural dynamics with improved numerical dissipation: the generalized-alpha method, J. Appl. Mech., 60, 371-375, 1993.

Cleary, P. W. and Prakash, M.: Discrete-element modelling and smoothed particle hydrodynamics: potential in the environmental sciences, Philos. T. R. Soc. A, 362, 2003-2030, doi:10.1098/rsta.2004.1428, 2004.

Cole, S., Cronin, S., Sherburn, S., and Manville, V.: Seismic signals of snow-slurry lahars in motion: 25 September 2007, Mt Ruapehu, New Zealand, Geophys. Res. Lett., 36, L09405, doi:10.1029/2009GL038030, 2009.

Commonwealth Scientific and Industrial Research Organization (CSIRO): Siro 3-D, Sirovision 3-D Imaging Mapping System, User Manual, Version 4.1, 2010a.

Commonwealth Scientific and Industrial Research Organization (CSIRO), Sirojoint, Sirovision structural mapping and analysis system, User manual, Version 4.1, $2010 \mathrm{~b}$.

Dahlen, F.: Single-force representation of shallow landslide sources, B. Seismol. Soc. Am., 83, 130-143, 1993.

Dammeier, F., Moore, J. R., Haslinger, F., and Loew, S.: Characterization of alpine rockslides using statistical analysis of seismic signals, J. Geophys. Res., 116, F04024, doi:10.1029/2011JF002037, 2011.

Deparis, J., Jongmans, D., Cotton, F., Baillet, L., Thouvenot, F., and Hantz, D.: Analysis of rock-fall and rock-fall avalanche seismograms in the French Alps, B. Seismol. Soc. Am., 98, 1781-1796, 2008.
Dorren, L. K. A.: A review of rockfall mechanics and modelling approaches, Prog. Phys. Geogr., 27, 69-87, 2003.

Dorren, L. K. A., Berger, F., and Putters, U. S.: Real-size experiments and 3-D simulation of rockfall on forested and nonforested slopes, Nat. Hazards Earth Syst. Sci., 6, 145-153, doi:10.5194/nhess-6-145-2006, 2006.

Evans, S. G. and Hungr, O.: The assessment of rockfall hazard at the base of talus slopes, Can. Geotech. J., 30, 620-636, 1993.

Fabre, D., Lorier, L., Mathy, A., and Hantz, D.: Gestion d'un risque rocheux en zone urbanisée: le cas des rochers du Néron près de Grenoble (Isère - France), Proceedings of the 1st International Conference on Landslides risk, 14-16 March 2013, Tabarka, Tunisia, 149-162, 2013.

Favreau, P., Mangeney, A., Lucas, A., Crosta, G., and Bouchut, F.: Numerical modeling of landquakes, Geophys. Res. Lett., 37, L15305, doi:10.1029/2010GL043512, 2010.

Gidon, M. and Arnaud, H.: Carte géologique détaillée de la France à 1/50 000ème, feuille Grenoble, 2 Edn., Bureau de Recherches Géologiques et Minières, Orléans, 1978.

Hanks, T. C. and Kanamori, H.: A moment magnitude scale, J. Geophys. Res., 84, 2348-2350, 1979.

Heidenreich, B.: Small- and half-scale experimental studies of rockfall impacts on sandy slopes, PhD thesis, EPFL, Lausanne, 2004.

Helmstetter, A. and Garambois, S.: Seismic monitoring of Séchilienne Rockslide (French Alps): analysis of seismic signals and their correlation with rainfalls, J. Geophys. Res., 115, F03016, doi:10.1029/2009JF001532, 2010.

Hibert, C., Mangeney, A., Grandjean, G., and Shapiro, N.: Slopes instabilities in the Dolomieu crater, la Réunion island : from the seismic signal to the rockfalls characteristics, J. Geophys. Res. Earth, 116, F04032, doi:10.1029/2011JF002038, 2011.

Hibert, C.: Apport de l'écoute sismique pour l'étude des éboulements du cratère Dolomieu, Piton de la Fournaise (Ile de la Réunion), PhD thesis, Institut de Physique du Globe de Paris, Paris, France, 2012.

Hungr, O., Corominas, J., and Eherhardt, E.: Estimating landslide motion mechanism, travel distance and velocity, in: Landslide Risk Management, edited by: Hungr, O., Fell, R., Couture, R., and Eherhardt, E., Taylor and Francis Group, London, ISBN 041538043X, 2005.

Iverson, R. M.: The physics of debris flows, Rev. Geophys., 35, 245-296, doi:10.1029/97RG00426, 1997.

Kanamori, H.: The energy release in great earthquakes, J. Geophys. Res., 82, 2981-2987, 1977.

Kanamori, H. and Given, J. W.: Analysis of long-period seismic waves excited by the May 18, 1980, eruption of Mount St. Helens-A terrestrial monopole?, J. Geophys. Res.-Sol. Ea., 87, 5422-5432, 1982.

Kanamori, H., Given, J. W., and Lay, T.: Analysis of seismic body waves excited by the Mount St. Helens eruption of May 18, 1980, J. Geophys. Res.-Sol. Ea., 89, 1856-1866, 1984.

Kao, H., Kan, C.-W., Chen, R.-Y., Chang, C.-H., Rosenberger, A., Shin, T.-C., Leu, P.-L., Kuo, K.-W., and Liang, W.-T.: Locating, monitoring, and characterizing typhoon-linduced landslides with real-time seismic signals, Landslides, 9, 557-563, 2012.

Lacroix, P. and Helmstetter, A.: Location of seismic signals associated with microearthquakes and rockfalls on Séchilienne landslide, B. Seism. Soc. Am., 101, 341-353, 2011. 
La Rocca, M., Galluzzo, D., Saccorotti, G., Tinti, S., Cimini, G. B., and Del Pezzo, E.: Seismic signals associated with landslides and with a tsunami at Stromboli volcano, Italy, B. Seis. Soc. Am., 94, 1850-1867, 2004.

Ma, G., Matsuyama, H., Nishiyama, S., and Ohnishi, Y.: Practical studies on rockfall simulation by DDA, J. Rock Mech. Geotech. Eng., 3, 57-63, 2011.

Mangeney-Castelnau, A., Vilotte, J.-P., Bristeau, M. O., Perthame, B., Bouchut, F., Simeoni, C., and Yerneni, S.: Numerical modeling of avalanches based on Saint Venant equations using a kinetic scheme, J. Geophys. Res., 108, 2527, doi:10.1029/2002JB002024, 2003.

Mangeney, A., Tsimring, L. S., Volfson, D., Aranson, I. S., and Bouchut, F.: Avalanche mobility induced by the presence of an erodible bed and associated entrainment, Geophys. Res. Lett., 34, L22401, doi:10.1029/2007GL031348, 2007.

Manzella, I. and Labiouse, V.: Flow experiments with gravel and blocks at small scale to investigate parameters and mechanisms involved in rock avalanches, Eng. Geol., 109, 146-158, doi:10.1016/j.enggeo.2008.11.006, 2009.

McSaveney, M. J.: Recent rockfalls and rock avalanches in Mount Cook national park, New Zealand, in: Catastrophic landslides: Effects, occurence and mechanisms: Boulder, Colorado, edited by: Evans, S. G. and DeGraff, J. V., Geological Society of America Reviews in Engineering Geology, 15, 35-70, 2002.

McSaveney, M. J. and Downes, G. L.: Application of landslide seismology to some New Zealand rock avalanches, in: Landslides: Proceedings of the First European Conference on Landslides, edited by: Rybar, J., Stemberk, J., and Wagner, P., 24-26 June 2002, Lisse, the Netherlands, 649-654, 2002.

Moretti, L., Mangeney, A., Capdeville, Y., Stutzmann, E., Huggel, C., Schneider, D., and Bouchut, F.: Numerical modeling of the Mount Steller landslide flow history and of the generated long period seismic waves, Geophys. Res. Lett., 39, L16402, doi:10.1029/2012GL052511., 2012.

Moser, F., Jacobs, L. J., and Qu, J.: Modeling elastic wave propagation in waveguides with the finite element method, NDT \& E International, 32, 225-234, 1999.

Norris, R. D.: Seismicity of rockfalls and avalanches at three Cascade Range volcanoes: Implications for seismic detection of hazardous mass movements, B. Seis. Soc. Am., 84, 1925-1939, 1994.

Pirulli, M. and Mangeney, A.: Results of Back-Analysis of the Propagation of Rock Avalanches as a Function of the Assumed Rheology, Rock Mech. Rock Eng., 41, 59-84 doi:10.1007/s00603007-0143-x, 2008.

Poropat, G. V.: New methods for mapping the structure of rock masses, in: Proceedings, Explo 2001, Hunter Valley, New South Wales, 28-31 October 2001, 253-260, 2001.

Poropat, G. V.: Remote 3-D Mapping of rock mass structure, Laser and photogrammetric methods for rock face characterization, American Rock Mechanics Association, Golden, Colorado, 1718 June 2006.
Richefeu, V., Mollon, G., Daudon, D., and Villard, P.: Dissipative contacts and realistic block shapes for modelling rock avalanches, Eng. Geol., 149-150, 78-92, doi:10.1016/j.enggeo.2012.07.021, 2012.

Rousseau, N.: Study of seismic signal associated with rockfalls at 2 sites on the Réunion Island (Indian Ocean): Mahavel Cascade and Soufrière cavity, PhD Thesis of the Institut de Physique du Globe de Paris, Paris, France, 134 pp., 1999.

Schneider, D., Bartelt, P., Caplan-Auerbach, J., Christen, M., Huggel, C., and McArdell, B. W.: Insights into rock-ice avalanche dynamics by combined analysis of seismic recordings and a numerical avalanche model, J. Geophys. Res.-Earth, 115, F04026, doi:10.1029/2010JF001734, 2010.

Sosio, R., Crosta, G. B., and Hungr, O.: Complete dynamics modeling calibration for the Thurwieser rock avalanche (Italian Central Alps), Eng. Geol., 100, 11-26, doi:10.1016/j.enggeo.2008.02.012, 2008.

Sturzenegger, M. and Stead, D.: Close-range terrestrial digital photogrammetry and terrestrial laser scanning for discontinuity characterization on rock cuts, Eng. Geol., 106, 163-182, 2009.

Surinach, E., Furdada, G., Sabot, F., Biescas, B., and Vilaplana, J.: On the characterization of seismic signals generated by snow avalanches for monitoring purposes, Ann. Glaciol., 32, 268-274, 2001.

Suriñach, E., Vilajosana, I., Khazaradze, G., Biescas, B., Furdada, G., and Vilaplana, J. M.: Seismic detection and characterization of landslides and other mass movements, Nat. Hazards Earth Syst. Sci., 5, 791-798, doi:10.5194/nhess-5-791-2005, 2005

Vacher, P., Dumoulin, S., Morestin, F., and Mguil-Touchal, S.: Bidimensional strain measurement using digital images, Proceedings of the Institution of Mechanical Engineers, J. Mech. Eng. Sci., 213, 811-817, 1999.

Vilajosana, I., Suriñach, E., Abellán, A., Khazaradze, G., Garcia, D., and Llosa, J.: Rockfall induced seismic signals: case study in Montserrat, Catalonia, Nat. Hazards Earth Syst. Sci., 8, 805-812, doi:10.5194/nhess-8-805-2008, 2008.

Weichert, D., Horner, R. B., and Evans, S. G.: Seismic signature of landslides: the 1990 Brenda mine collapse and the 1965 Hope rockslides, B. Seismol. Soc. Am., 84, 1523-1532, 1994.

Wolter, A., Stead, D., and Clague, J.: A morphologic characterisation of the 1963 Vajont Slide, Italy, using long-range terrestrial photogrammetry, Geomorphology, 206, 147-164, 2013.

Yamada, M., Matsushi, Y., Chigira, M., and Mori, J.: Seismic recordings of landslides caused by Typhoon Talas (2011), Japan, Geophys. Res. Lett., 39, L13301, doi:10.1029/2012GL052174, 2012.

Yamada, M., Kumagai, H., Matsushi, Y., and Matsuzawa, T.: Dynamic landslide processes revealed by broadband seismic records, Geophys. Res. Lett., 40, 2998-3002, doi:10.1002/grl.50437, 2013. 